Digital Comprehensive Summaries of Uppsala Dissertations from the Faculty of Science and Technology 1343

\title{
Scalable Queries over Log Database Collections
}

MINPENG ZHU

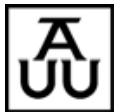

ACTA UNIVERSITATIS UPSALIENSIS UPPSALA
ISSN 1651-6214

ISBN 978-91-554-9472-8

urn:nbn:se:uu:diva-275044 
Dissertation presented at Uppsala University to be publicly examined in 2446, Department of Information Technology, Polacksbacken (Lägerhyddsvägen 2), Uppsala, Wednesday, 30 March 2016 at 13:00 for the degree of Doctor of Philosophy. The examination will be conducted in English. Faculty examiner: Emeritus Professor Peter Gray (The School of Natural and Computing Sciences, University of Aberdeen).

\begin{abstract}
Zhu, M. 2016. Scalable Queries over Log Database Collections. Digital Comprehensive Summaries of Uppsala Dissertations from the Faculty of Science and Technology 1343. 51 pp. Uppsala: Acta Universitatis Upsaliensis. ISBN 978-91-554-9472-8.

In industrial settings, machines such as trucks, hydraulic pumps, etc. are widely distributed at different geographic locations where sensors on machines produce large volumes of data. The data produced is stored locally in autonomous databases called log databases. The collection of log databases is dynamically changing when new sites are dynamically added or removed from the federation.

In this application context, an efficient way to search and analyze passed behavior of products in use is desired. To enable scalable queries over collections of distributed and autonomous log databases we developed the FLOQ (Fused LOg database Query processor) system, which provides a global view of the working status of all machines on the sites through a meta-database integrating the dynamic log database collection. A particular challenge in this scenario is a scalable way to process numerical queries that identify anomalies by joining data from the metadatabase with data selected from the collection of distributed and autonomous log databases. The Thesis describes the architecture of FLOQ. In particular different strategies to execute numerical queries over log database collections are investigated. FLOQ allows both the meta-database and the log databases to be stored in multiple formats using different kinds of data managers. FLOQ provides general and extensible mechanisms for efficient processing of queries over different kinds of distributed data sources.
\end{abstract}

Minpeng Zhu, Department of Information Technology, Box 337, Uppsala University, SE-75105 Uppsala, Sweden.

(C) Minpeng Zhu 2016

ISSN 1651-6214

ISBN 978-91-554-9472-8

urn:nbn:se:uu:diva-275044 (http://urn.kb.se/resolve?urn=urn:nbn:se:uu:diva-275044) 
To my parents and great friends 好人好运 



\section{List of Papers}

This Thesis is based on the following papers, which are referred to in the text by their Roman numerals.

I Zhu, M., Risch, T. (2011) Querying Combined Cloud-Based and Relational Databases, The 2011 International Workshop on Data Cloud (D-CLOUD 2011), at 2011 International Conference on Cloud and Service Computing (CSC), Hong Kong, China, December 12-14, 2011, In Proc. CSC 2011, pp. 330335 .

II Zhu, M., Stefanova, S., Truong, T., Risch, T. (2014) Scalable Numerical SPARQL Queries over Relational Databases, 4th International workshop on linked web data management (LWDM 2014) in conjunction with the EDBT/ICDT 2014 Joint Conference, Athens, Greece, March 28, 2014, In Proc. LWDM 2014, pp. 257-262.

III Zhu, M., Mahmood, K., Risch, T. (2015) Scalable Queries Over Log Database Collections, 30th British International Conference on Databases (BICOD 2015), Edinburgh, UK, July 6-8, 2015, In Proc. BICOD 2015, pp. 173-185.

IV Mahmood, K., Risch, T, Zhu, M. (2015) Utilizing a NoSQL Data Store for Scalable Log Analysis, 19th International Database Engineering \& Applications Symposium (IDEAS 2015), Yokohama, Japan, July 13-15, 2015, In Proc. IDEAS 2015, pp. 4955 .

Reprints were made with permission from the respective publishers. All papers are reformatted to the one-column format of this book. 



\section{Contents}

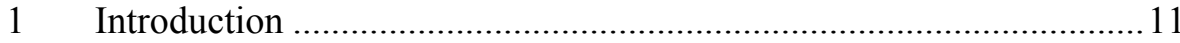

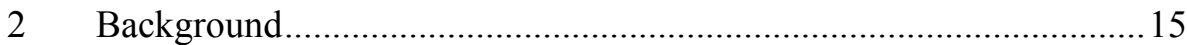

2.1 Database Management Systems ................................................... 15

2.1.1 Data Models and Query Languages ........................................ 15

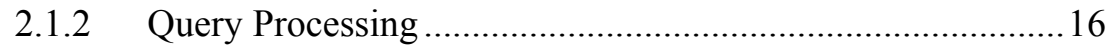

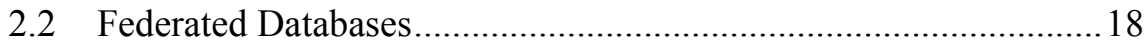

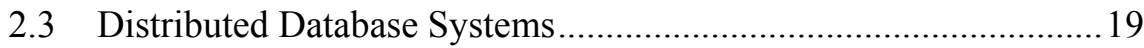

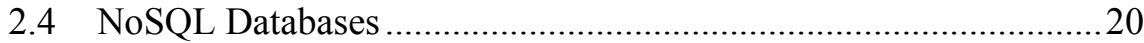

2.5 Numerical and Temporal Databases ..............................................2 21

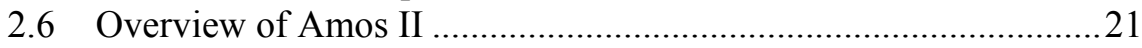

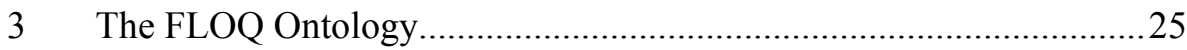

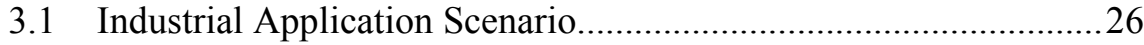

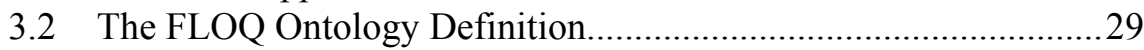

3.3 Application Scenario Log Data Sets .............................................. 31

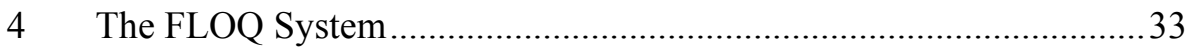

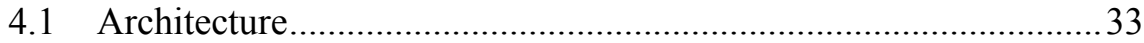

4.2 FLOQ Query Processor..................................................................... 35

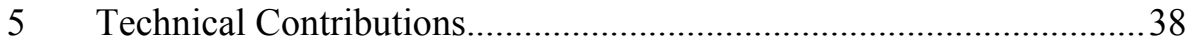

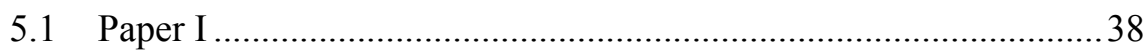

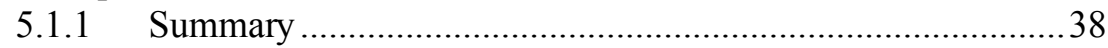

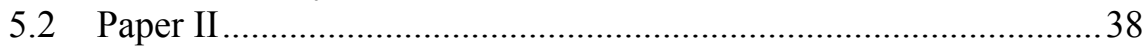

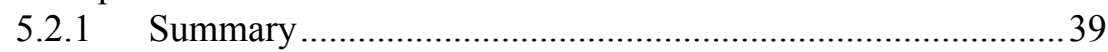

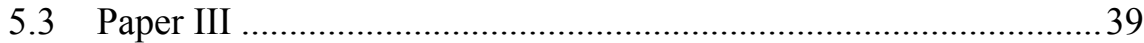

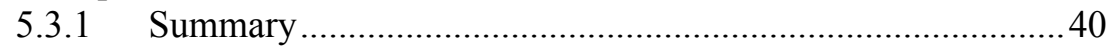

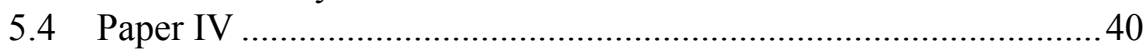

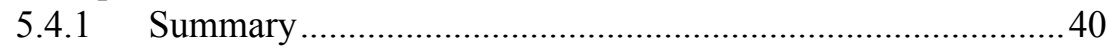

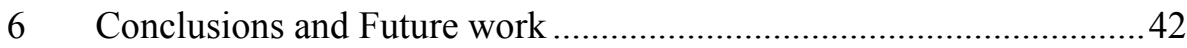

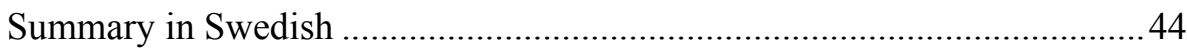

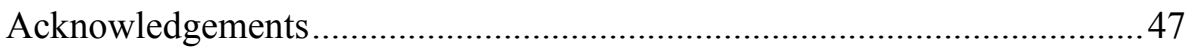

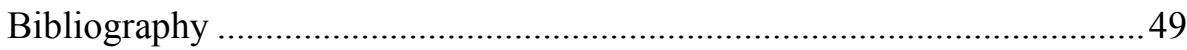





\section{Abbreviations}

Amos

CDM

DBMS

FLOQ

GAE

JDBC

RDF

RDFS

SQL

SPARQL

URI

URL

$C_{\text {Join }}$

$B_{i}$

$R_{i}$

$C_{i}$

$C_{\sigma i}$

$C_{\bowtie i}$

$C_{\text {Bulkloadi }}$

$C_{\sigma_{R}}$

$R D B_{i}$

$C_{\text {FLOQ }}$

$C_{S}$

$\beta$

$C_{m}$

$C_{J D B C}$

$\sigma_{i}$

$C_{B_{i}}$

$C_{R_{i}}$

$C_{N e t}$
Active Mediator Object System

Common Data Model

Database Management System

Fused LOg database Query processor (Paper III)

Google App Engine (Paper I)

Java Database Connectivity (Paper III)

Resource Description Framework (Paper II)

RDF Schema (Paper II)

Structured Query Language

Simple Protocol and RDF Query Language (Paper II)

Uniform Resource Identifier (Paper II)

Uniform Resource Locator (Paper I)

Total cost of a join (Paper III)

Binding stream to site $i$ (Paper III)

Result stream from site $i$ (Paper III)

Total cost at site $i$ (Paper III)

Cost of executing $\sigma_{i}$ in $R D B_{i}$ (Paper III)

Cost of local join at site $i$ (Paper III)

Cost of bulk loading in $R D B_{i}$ (Paper III)

Selection Cost for a single binding $\beta$ (Paper III)

The relational $\log$ database at site $i$ (Paper III)

Total execution cost in the FLOQ server (Paper III)

Cost of splitting the binding stream $B$ in the FLOQ server (Paper III)

A single binding from the binding stream $B_{i}$ (Paper III)

Cost of merging result streams $R_{i}$ in the FLOQ server (Paper III)

Cost of JDBC call for a single binding $\beta$

The query to $R D B_{i}$ (Paper III)

Cost of transferring binding stream $B_{i}$ to site $i$ (Paper III)

Cost of transferring result stream $R_{i}$ from site $i$ (Paper III)

Network communication overhead cost for a single binding $\beta$ (Paper III) 



\section{Introduction}

Modern product development generates high volumes of data during its life cycle, from development and manufacturing, through use and maintenance, to reengineering and recycling. The ability to represent, search, and analyze many different kinds of data generated during a product's life cycle is critical for high quality and high availability. Within this context, an important issue is scalable approaches to collect, process, and analyze data produced in the manufacturing process.

Recently, there is a rise of manufacturing industry transformation. Research initiatives were developed and applied. The ideas such as Germany's Industry 4.0 [4] [20], China's Made in China 2025 [21], and US's Industrial Internet [19] are proposed. They share similar ideas of improving productivity, efficiency, and quality of products.

This Ph.D. work is from a real-world industrial scenario [30], where machines such as trucks, hydraulic pumps, cutting tools, etc. are widely distributed at different geographic locations and where sensors on machines produce large volumes of data. The data produced at each site describe time stamped sensor readings of machine components (e.g. oil temperature and pressure) and is stored locally in autonomous databases called log databases. The log databases are used to search and analyze abnormal behaviors of the monitored machines distributed over many sites. Furthermore, the collection of $\log$ databases is dynamically changing when new sites are added or removed from the federation.

In order to search and analyze data from the log databases there is need for a meta-database that describes properties of the monitored equipment and their log databases, e.g. the machine configurations at the sites, descriptions of the installed sensors, measurement tolerances, etc. The meta-database provides a global view of the working status of all machines on the sites. It represents meta-data integrating the log database collection. A particular challenge in this scenario is a scalable way to process queries that join data selected from the meta-database with data selected from the collection of log databases.

Abnormal machine behaviors can often be detected by identifying significant deviations between measured values stored in log databases and corresponding expected values stored as meta-data. Such deviations can be expressed as numerical expressions in query conditions identifying when measured values are outside the tolerances for a sensor model during a time 
period. This requires a way to process such numerical query expressions over collections of log databases integrated through the meta-database.

The following research questions are investigated:

1. The overall research question is: how should the meta-database over the federation of log databases be represented and how should queries to the federation be expressed and processed?

2. How can different kinds of data managers be used for representing the log databases as well as the meta-database?

3. How can a cloud-based data repository be used for representing the meta-database?

4. How can queries that join the meta-database with data selected from collections of the distributed log databases be executed efficiently?

5. How can numerical queries to determine anomalies in measurements be executed efficiently over log databases?

To approach these challenges and answering research question one we developed a system, Fused LOg database Query processor (FLOQ), Figure 1. FLOQ integrates collections of dynamic, distributed, and autonomous log databases through a meta-database called the FLOQ ontology. The ontology is managed by the FLOQ server.

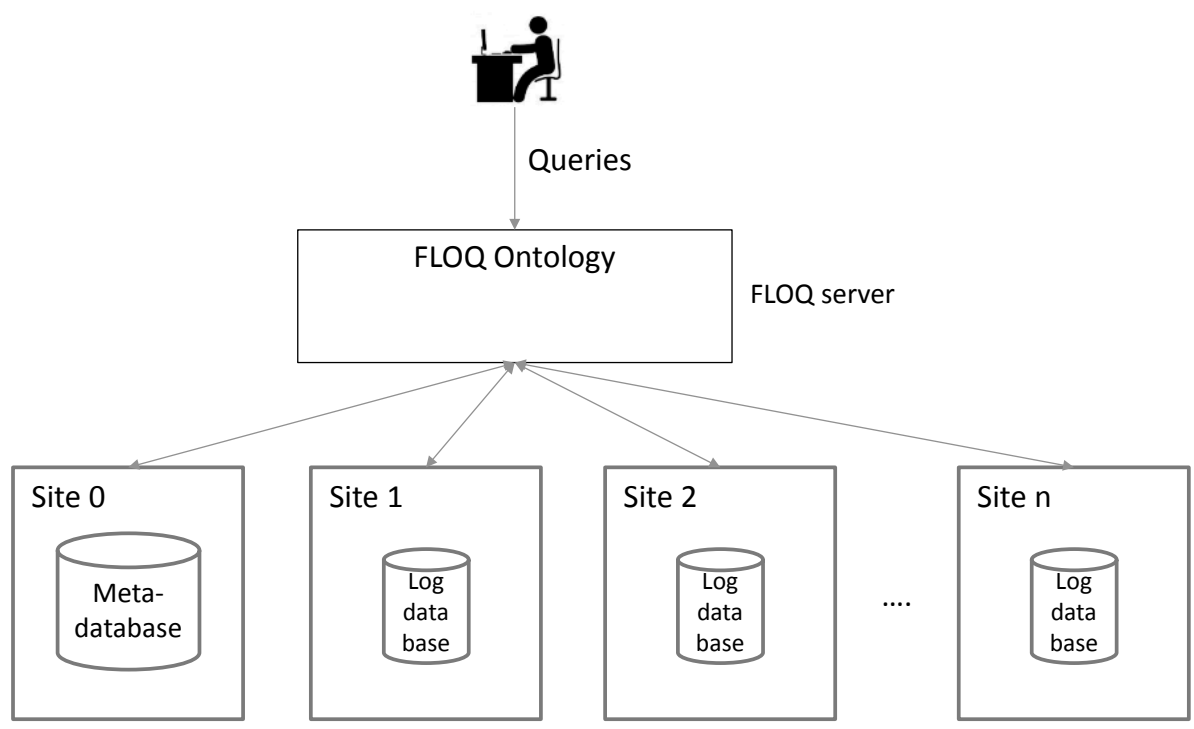

Figure 1. FLOQ Overview

The FLOQ ontology describes meta-data and physical properties about industrial equipment located at different sites. The FLOQ ontology is an application independent and can describe different kinds of industrial equipment. At each site enumerate $1,2, \ldots, \mathrm{n}$ there is equipment that produces sensor 
measurement stored in local $\log$ databases. The log databases are locally maintained at each site and are described by the FLOQ ontology. Also parts of the ontology is defined as an external meta-database located at site 0 . Independent FLOQ site servers encapsulate the back-end data managers to process queries at the sites. The user sends queries to the FLOQ server searching the log databases. The queries are expressed in terms of the ontology. Such a query might include searching and combining data from both the meta-database and the log databases. FLOQ uses the ontology to locate the $\log$ databases involved in answering a query. The queries often analyze data in log databases to find anomalies and other properties about the equipment. Such queries frequently involve numerical expressions, e.g., to detect deviations between measured and expected sensor readings.

The FLOQ ontology uses a domain-calculus based functional common data model (CDM) [28] to integrate all meta-data. FLOQ allows both the meta-database and the log databases to be stored in multiple formats using different kinds of data managers. The external data representations are mapped to the ontology represented by the CDM. Thus FLOQ provides general and extensible mechanisms for efficient processing of queries over different kinds of data sources, such as relational databases or MongoDB [22] [25]. This answers research question two.

In order to make meta-data widely accessible parts of the meta-database can also be stored in external data sources, such as Google's Bigtable [7]. In particular, in a world-wide organization the meta-database should be highly available and universally accessible from any location. Cloud-based data stores such as Bigtable provide high availability, universal access, and scalability. The FLOQ approach allows to map external meta-database representation to the FLOQ ontology [40]. For example, meta-data can be represented using either FLOQ's native CDM, as a relational database, or as cloudbased data manager such as Google Bigtable. The ability of FLOQ to represent meta-database using different formats answers research question three.

FLOQ provides a query processor for efficient, scalable, and distributed query execution. A general extensibility mechanism based on plug-ins allows the system to split a query into sub-queries accessing different kinds of data sources. Queries to the ontology are decomposed into sub-queries to different log databases. We propose two new join strategies, parallel bindjoin (PBJ) and parallel bulk-load join (PBLJ) [42] for parallel execution of queries joining meta-data with data from autonomous log databases using standard DBMS APIs. This query processing over log database federations answers research question four.

For scalable execution of numerical queries over relational databases (RDBs), numerical operators should be pushed into SQL rather than executing the filters as post-processing outside the RDB; otherwise the query execution is slowed down, since a lot of data is transported from the RDB servers and furthermore indexes on the servers are not utilized. The NUMTrans- 
lator algorithm [41] converts numerical expressions in numerical domain calculus queries into corresponding SQL expressions. We show that NUMTranslator improves substantially the scalability of numerical queries based on a benchmark that analyses numerical logs stored in an RDB. This answers research question five.

This Thesis overview is organized as follows. Chapter 2 gives an overview of technologies related to FLOQ. Chapter 3 describes the FLOQ ontology based on the application scenario motivating the FLOQ approach. Chapter 4 gives an overview of the architecture of FLOQ, including its ability to utilize different data managers through its extensibility mechanisms. Chapter 5 summarizes paper I, II, III, IV, describing technical contributions of each paper and my contributions to each paper. Chapter 6 describes conclusions and future work. 


\section{Background}

This chapter describes the technical background related to this Thesis project. Relational database management systems in general are overviewed first. Federated and distributed database systems are then described by their architectures and query processing strategies. Furthermore, NoSQL databases, numerical databases, and temporal databases are described. Finally, the Amos II system is described, which this Thesis work extends substantially.

\subsection{Database Management Systems}

A database is a collection of data that can be stored [11]. A database management system (DBMS) is a software system that enables database creation, manipulation, and maintenance. For example, it enables the following:

- Creating a database with specified schema structure through a Data Definition Language (DDL).

- Manipulating a database, for example, querying, inserting, deleting, and updating the data.

- Multi-user access to a database with different kinds of authentication control.

- Recovery control to restore the database back to a specific time point.

\subsubsection{Data Models and Query Languages}

A data model defines the structure and format of data used by a database management system. Different DBMSs have different data models. The most common data model is the relational data model where the database is represented as a set of tables.

The database schema describes the data stored in the database. In the relational data model it describes the names of tables and columns, and data types of row attributes (or column values) stored in the database. Each row in a table is identified with a key, which is one or several columns uniquely identifying a row. A foreign key is one or several attributes in a table referencing the attribute(s) in another table. 
To be able to combine data from many log databases, FLOQ uses a functional and object-oriented data model [28] to represent meta-data about collections of log databases: the FLOQ ontology described in Chapter 3.

Each data model supports some query language. For example, the standard query language for the relational data model is SQL (Structured Query Language). In SQL, queries are issued over tables as predicates constraining table rows (tuples). SQL is a declarative language based on a predicate calculus called tuple calculus [8] [11] where variables are bound to tuples (rows) in tables and the user specifies how to match and constrain tuples. An alternative is domain calculus [8] [11], which is a predicate calculus where variables are bound to atomic values, rather than tuples as in tuple calculus. Since numerical expressions are easy to formulate using variables bound to numbers, queries over numerical expressions are simplified by using domain calculus, rather than the tuple calculus used by SQL where all variables are bound to tuples.

The functional data model used in FLOQ uses the domain calculus query language AmosQL [28].

A common domain calculus language used in the semantic web community is SPARQL [33]. SPARQL is a promising domain calculus based query language for scientific applications [1] [2]. FLOQ supports both SQL and SPARQL as alternative query languages for queries to the FLOQ ontology. Both SQL and SPARQL queries are translated by a parser into AmosQL queries for further processing.

Another common domain calculus language is Datalog [11]. Amos II (and FLOQ) uses a Datalog dialect, ObjectLog [28], as internal representation of queries. The query processor transforms ObjectLog expressions to improve performance.

\subsubsection{Query Processing}

For a given query, the DBMS takes care of how to efficiently retrieve the information from the database. The query processor of the DBMS transforms the query into an efficient program (execution plan) specifying how to retrieve data. Indexing is a commonly technique to improve the query execution performance over very large databases. For analytical tasks, [26] demonstrates that indexing improves query performance. Typical query processing steps in a DBMS are shown in Figure 2. 


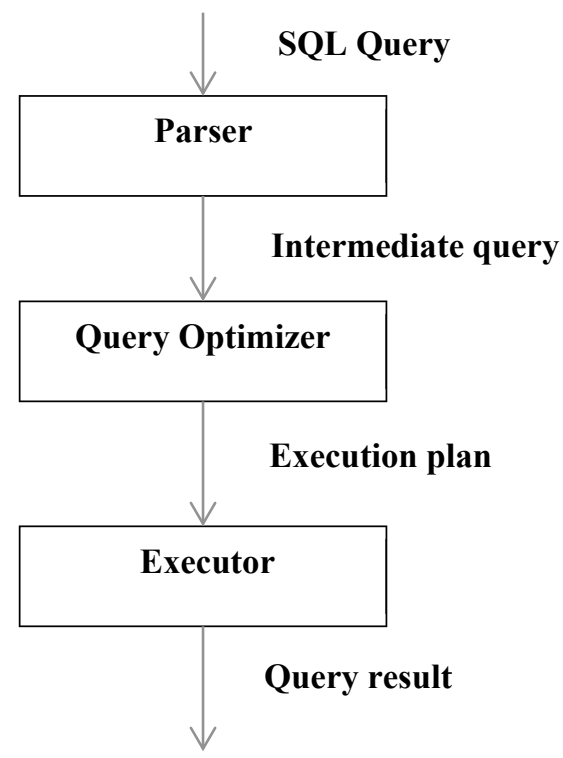

Figure 2. Query processing in DBMS

First, the parser checks the query's syntactic correctness and checks that tables and columns are correctly referenced. The result of parsing and validation is an intermediate query, usually a logical calculus expression to be executed. The query optimizer takes the intermediate query and produces an efficient program called an execution plan among the many feasible execution plans. Cost-based optimization [12] estimates the cost of executing a plan according to some cost model based on knowledge about database statistics, internal data representations, and search algorithms used in the plan. The query optimizer aims to generate an execution plan with minimal cost according to the cost model. To estimate the query plan cost, the optimizer needs, for example, the approximate number of disk block accesses, central processing unit (CPU) usage, etc. The number of disk block accesses is affected by the execution order inside the execution plan. Therefore, valid statistics of the database, e.g. number of rows in tables and number of different values in columns are very important for the query optimizer to estimate the query plan cost.

Finally, the executor interprets the execution plan and produces the query result.

A central part of FLOQ is novel specialized query processing mechanisms to process numerical queries over collections of distributed log databases described by a common meta-database. Domain calculus query transformations are utilized for transforming domain calculus queries into SQL tuple calculus queries. Query fragments are translated into sub-queries ac- 
cessing the log databases and then joined by FLOQ. Special query transformations are used for processing numerical queries. In the Thesis various query processing strategies for this are evaluated.

\subsection{Federated Databases}

A federated database (FDB) [11] is a union of independent and autonomous databases. Each database in a federation has a local database schema, called local conceptual schema. A central federated database provides a global conceptual schema that integrates subsets of the local conceptual schemas to enable queries over the integrated database federation, i.e. the global conceptual schema implements an ontology represented by a common data model (CDM) that enables mapping participating databases representations to the $\mathrm{CDM}$ and integrates information from the participating databases. To integrate data from different databases, the global conceptual schema needs to solve semantic data reconciliation issues on how to combine similar or same information represented differently in the different participating databases. Since the participant database schemas are designed before the global sche$\mathrm{ma}$, the global conceptual schema is designed in a bottom up fashion. The global conceptual schema enables query transparency to the user without showing the underlying conceptual schemas in the federation. However, it can be difficult to define such a global conceptual schema if the number of different participating databases is large. Finally, external schemas (views) can be defined by users on top of the global conceptual schema. Figure 3 shows how different schemas relate in a federated database.

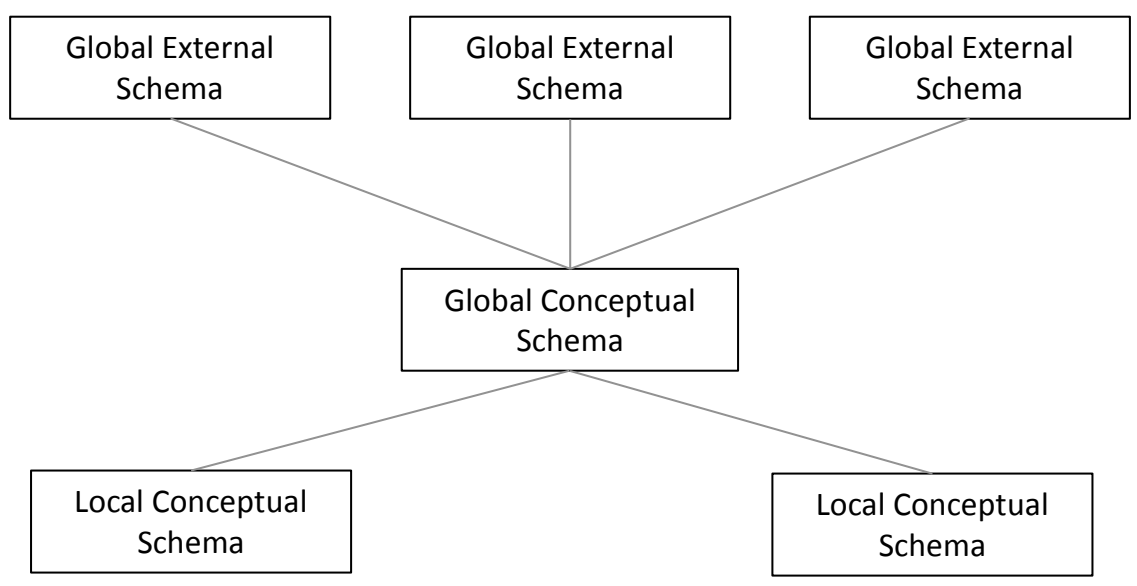

Figure 3. Federated Database Schemas

In FLOQ the log databases are independent and autonomous databases. The FLOQ ontology provides a global conceptual schema over the collection of 
$\log$ databases in the federation. The global conceptual schema of FLOQ contains a uniform representation of all the databases storing the logged data. One particular problem addressed in FLOQ is that the collection of log databases is dynamic so that new log databases can be added and removed over time as new sites are included or removed. In particular, whereas federated databases traditionally have been used for integrating a fixed set of existing databases, FLOQ's log database collections are dynamic where log databases at different sites can join or leave the federation.

Federated DBMSs may include primitives to integrate databases implemented in different kinds of DBMSs, having different data models. For example, data from relational databases may need to be integrated with data from NoSQL databases [32] and text files. NoSQL data managers such as MongoDB [25] often use a data model where data is represented as JSON objects. In order to integrate MongoDB with, e.g. relational databases, the federated database system needs primitives to transform both the relational database model and the MongoDB data model into a CDM used by the federated DBMS.

In FLOQ's case the CDM is an extension of the functional and objectrelational data model used in Amos II [28]. The FLOQ ontology is expressed in this CDM and defines meta-data including descriptions of log databases using different data models.

\subsection{Distributed Database Systems}

A distributed database (DDB) [11] [37] is a set of database processing nodes connected by a computer network. The database processing nodes are often geographically distant. The user sees the distributed database as a central database, while the database administrator (DBA) is responsible for deciding on which nodes different fragments of tables reside. Each table in a distributed database is partitioned logically, for example, a table can be fragmented by rows or columns where each fragment is stored in different distributes database nodes, which is called horizontal and vertical fragmentation, respectively. For example, a company-wide table may have different row fragments in different sites defined by the DBA. For any fragmentation method, a query to a fragmented table must return the same result as if the table is stored in a non-distributed database, i.e. the fragmentation scheme needs to be transparent in queries.

To increase query availability tables may be replicated at different sites. Data replication is also useful in speeding up query answering by accessing data available close to or at the site where queries are issued. Replication may however significantly reduce update speed, since distributed transactions might need to be propagated to several of the replicas to enable consistency. 
Since the data is physically distant in distributed databases, special distributed query processing strategies are required. Often several distributed database processing nodes are involved to answer a query. For example, distributed joins ship data from one site to another and to perform the join there. Join approaches such as semijoin [11] uses a strategy to first reduce the data shipped from a site by projecting the join column and removing duplicate values. Then a semijoin between the local data and the shipped data is performed. Finally, the semijoin result is sent to the other site for performing the final join there.

FLOQ uses two distributed query processing approaches namely parallel bind-join (PBJ) and parallel bulk-load join (PBLJ) to perform queries that join meta-data from a common meta-database with the data selected from the collections of distributed autonomous log databases. This generalizes the central bind-join [14], where data is joined by binding values when accessing external data sources.

\subsection{NoSQL Databases}

Not only SQL (NoSQL) databases [32] propose non-relational data models to provide availability and scalability of distributed databases. NoSQL databases such as MongoDB are designed to perform simple tasks with high scalability [6]. For providing high performance updates, NoSQL databases generally sacrifice strong consistency by providing so called eventual consistency compared with the ACID transactions of regular DBMSs.

NoSQL databases often have limited schemas where attributes in collections are dynamic, compared to relational databases where tables must have all columns specified in the schema before populating the database. For example, MongoDB [25] provides dynamic schemas which allows new attributes for data to be dynamically added to existing databases. It means records can be in different schema even in the same collection. This feature enables flexible insertions of the data into the database. NoSQL databases cover different kind of data store families, such as document stores, graph databases, cloud-based data stores.

[6] gives an overview of list features on the state-of-the-art NoSQL databases such as MongoDB [25], Cassandra [5], Redis [27], HBase [16], Memcached [24], and CouchDB [9]. However, Cassandra [5], Redis [27], HBase [16], Memcached [24], and CouchDB [9] do not provide full secondary indexing, which is essential for scalable performance of numerical queries. MongoDB [25] provides both a query language along with primary and secondary indexing. This is well suited for analyzing persisted logs.

In this Thesis, FLOQ investigates the approach to store parts of the common meta-data using Google's Bigtable cloud-based NoSQL database. Furthermore, FLOQ allows the log databases to be stored in different forms, 
such as relational databases and MongoDB. A NoSQL database such as MongoDB may be useful for typical historical analysis of log data or numerical log analytics where transactional consistency conforming ACID compliance is not required.

\subsection{Numerical and Temporal Databases}

The content of a relation in a relational database can be changed over the time by inserting new tuples, deleting existing tuples, or updating existing tuples. A regular database maintains a snapshot of the current data. Temporal databases [31] are databases that maintain histories of data values over time for each table. There are different approaches to store time attributes, such as a time instant is stored together with each tuple in a table, or the valid time for a tuple is defined by an associated starting time and ending time instant. In FLOQs log databases valid time is important for defining during what time period a measured value is valid. The FLOQ ontology thus associates a valid time interval with each row in a log database table.

Numerical and scientific databases [29] typically are used to store complex objects such as array data representations. Queries over numerical databases can contain query conditions such as matrix operations, numerical computations, etc. Such query conditions can be, for example, a linear equation or a numerical computation involving numerical operators comparing values. Query optimization techniques such as compile time evaluation and query rewrites can be applied to improve the scalability of query execution.

In our applications sensors in equipment located at the sites produce measurement values of industrial equipment. The measured values are stored in the local log databases for analyzing the abnormal equipment behavior in the past. Each measurement has an associated valid time interval. To observe equipment abnormalities, queries to FLOQ often involve numerical query conditions. To improve query scalability, numerical query conditions are pushed down to the log databases. In FLOQ the NUMTranslator algorithm [41] utilizes a table driven approach to extract and translate numerical domain calculus operators into numerical tuple calculus operators, which are translated to SQL expressions executed by a relational DBMS.

\subsection{Overview of Amos II}

Amos II [28] is an extensible main-memory database system which in used in our prototype implementation of FLOQ. Amos II provides a functional and object-oriented data model where objects, types, and functions are the essential concepts. Types classify different kinds of objects stored in the database and functions define properties and computations over the objects. 
FLOQ utilizes the Amos II data model as a common data model (CDM) for storing the FLOQ ontology to integrate collections of log databases.

Each object is an instance of some types and all object instances of a type represent the extent of the type. Functions model object properties, relationships between objects, and computation over objects. A function is defined by a signature and an implementation. The signature defines the input and result parameter types and names. The implementation defines rules how to relate inputs and outputs. For example, stored functions are used to represent object attributes stored in an Amos II database as a table. Derived functions are side-effect free, precompiled, and optimized queries in terms of other Amos II functions. Foreign functions enable low-level interfaces for accessing external data sources through data manager.

AmosQL [28] is the domain calculus based query language in Amos II, where queries are expressed in terms of functions over variables bound to typed objects. The query processor internally represents queries as domain calculus ObjectLog [28] expressions, which extends Datalog [11] with types, objects, external predicates, and disjunctions. Since Amos II has an extensible engine (both data manager and query processor), new data types and operators defined by some external programming languages (C, Java, or Lisp) in new applications can be added to AmosQL. This extensibility allows wrapping different data representations of different kind of data sources.

FLOQ uses the data model of Amos II to represent the FLOQ ontology. The extensibility of Amos II is used for accessing different kinds of external data sources. In particular relational log databases are accessed through a relational data manager interface (DMI) [15], while Google Bigtable data stores can be access through another DMI [40]. The latter enables FLOQ to store parts of the FLOQ ontology as a cloud database. The MongoDB DMI [22] provides query processor and interfaces to MongoDB databases. It enables log databases managed by MongoDB to be queried through FLOQ.

To enable distributed query processing, many Amos II instances can be set up and communicated using TCP/IP in a federation. In FLOQ, the Amos II instances in the federation are called FLOQ site servers and the FLOQ server represents the FLOQ ontology and integrates data from a collection of FLOQ site servers. 
The query processing of Amos II is illustrated in Figure 4.

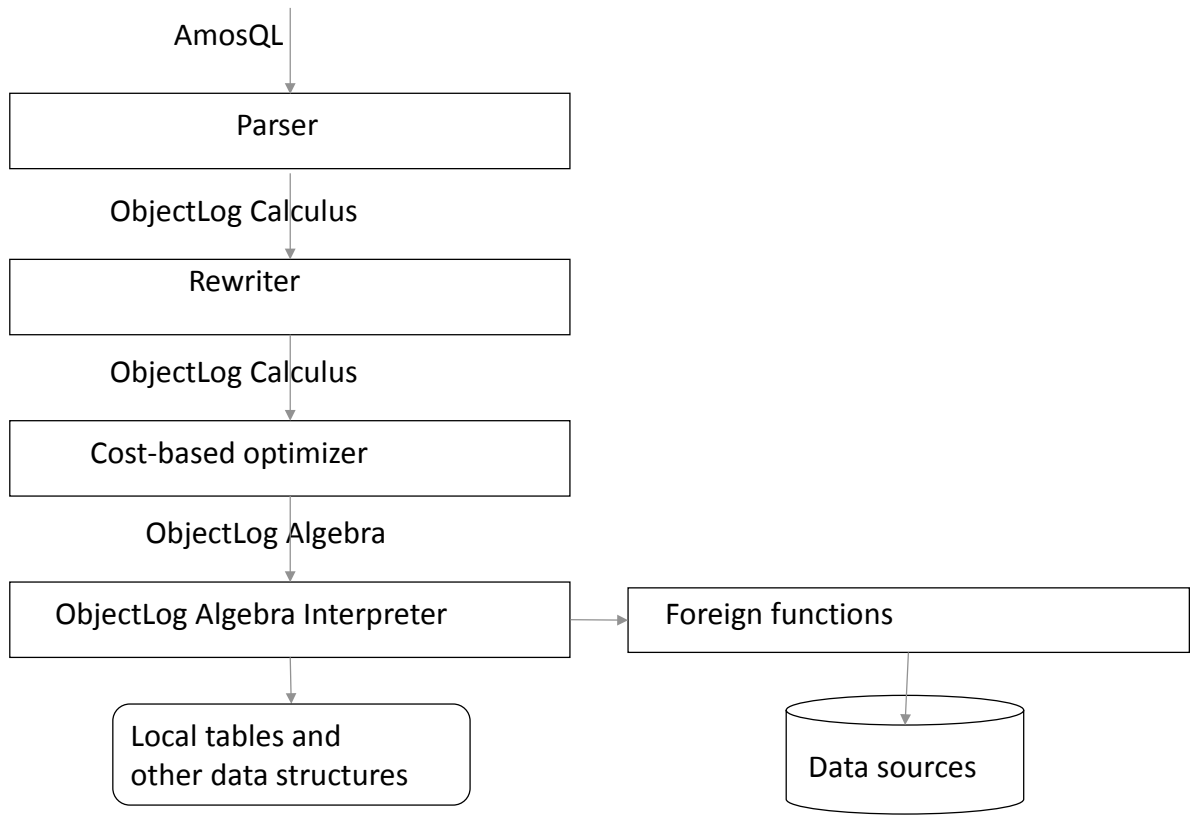

Figure 4. Amos II query processing

The system first parses the query into an ObjectLog Calculus expression. The rewriter applies logical query transformations on ObjectLog expressions. For example, it expands views to expose indexes, eliminates common subexpressions, and evaluates expressions at compile time. The cost-based optimizer applies optimization algorithms on the transformed ObjectLog expression to generate an optimized execution plan in terms of an ObjectLog algebra. The ObjectLog algebra interpreter runs the execution plan where foreign functions provide user-defined interpretations and access to foreign data sources. Native Amos II databases are accessed or queried through local main-memory tables and data structures supported by the system, such as vectors and dictionaries.

In FLOQ the Amos II query processor is modified with new rewrite mechanisms [40] to automatically split ObjectLog calculus expressions into query fragments accessing different kinds of data sources. The mechanism rewrites calculus expressions into equivalent ObjectLog expressions to generate a query execution plan accessing different data sources. Thus queries to the FLOQ ontology are decomposed into ObjectLog sub-queries to different data sources.

In our application, queries discovering abnormal machine behaviors often involve query include numerical expressions, inequalities, comparisons, etc. in query filter. For scalable execution of numerical queries to log databases, 
the numerical expression should be extracted and translated to push it down to the log database. The NUMTranslator algorithm [41] extends the rewrite strategy [40] to translate numerical operators in domain calculus queries into numerical operators into SQL tuple calculus expressions through system tables of FLOQ.

FLOQ provides a rewrite strategy implementing special query optimization strategies [42] to support scalable queries that join meta-data from a common meta-database with data selected from a collection of distributed autonomous log databases. Two new join strategies for parallel execution of queries joining meta-data with data from autonomous log databases using standard DBMS APIs are proposed and implemented: parallel bind-join (PBJ) and parallel bulk-load join (PBLJ). 


\section{The FLOQ Ontology}

Recently, there is a rise of manufacturing industry transformation. Research initiatives were developed and applied. The ideas such as Germany's Industry 4.0 [4] [20], China's Made in China 2025 [21], and US's Industrial Internet [19] are proposed. They share similar ideas of improving productivity, efficiency, and quality of products.

Within this context, an important issue is scalable approaches to collect, process, and analyze data produced in the manufacturing process. For example, industrial equipment (machines) with sensors installed on its components report the working status by delivering its measured data as data streams to some monitoring center where it is analyzed. Such data describe time stamped sensor readings of the monitored machines' components, such as the pressure of hydraulic motor pumps, the oil pressure in oil tankers, and the temperature of the engines in wheel loaders. These measurements reflect how the components function. The data is especially useful for analyzing the working status of monitored machine components. Data values outside certain machine-dependent constraints represent abnormal behavior and are therefore identified and used for further analyses. Thus, one way to analyze the measured data is to collect and store them for historical analyses. The stored measured data is called log data and a database storing such log data is called a log database. The data in log databases will be interpreted and analyzed to improve the monitored equipment's reliability. Since the sensors deliver the measured data as data streams, a Data Stream Management System can be used for real-time analyses of the data streams [38]. The scope of this Thesis work is focusing on analyzing stored log data rather than realtime stream data processing.

In Section 3.1 a common scenario from an industrial setting is presented to show the need to analyze historical log data in order to find abnormal machine behavior. Log data from embedded sensors is stored in a local log database at each site. Based on this scenario, in Section 3.2 the general conceptual schema description of monitored equipment, called the FLOQ ontol$o g y$, is defined. Section 3.3 describes an application scenario log data set. 


\subsection{Industrial Application Scenario}

To improve productivity, efficiency, and quality in manufacturing industry data is collected from sensors installed in industrial equipment, which enable monitoring and predicting their behavior to support, e.g., preventive maintenance [30]. The computation process provides monitoring, analysis, and control with feedback to the manufacturing process. Within this context, an important issue is a scalable approach to collect, process, and analyze the data produced in the manufacturing process.

As an example [30], Bosch Rexroth Mellansel AB (Hägglunds) [17] produce hydraulic drive systems, which are used in different areas of heavy industry, such as recycling, material handling, mining, etc. Figure 5 shows a wood waste shredder that is smashing wood waste to produce shredded wood that can be used, e.g., for animal bedding or as top of soil to improve fertility and preserve moisture. It is driven by a hydraulic motor which is connected and power supplied with a hydraulic drive unit containing a hydraulic pump driven by an electric motor. The hydraulic drive unit includes a Spider control system [18], which controls and monitors the hydraulic drive unit. The spider control system is a modularized control system that allows control of different kind of hydraulic drive systems, such as the one powering the shredder in Figure 5.

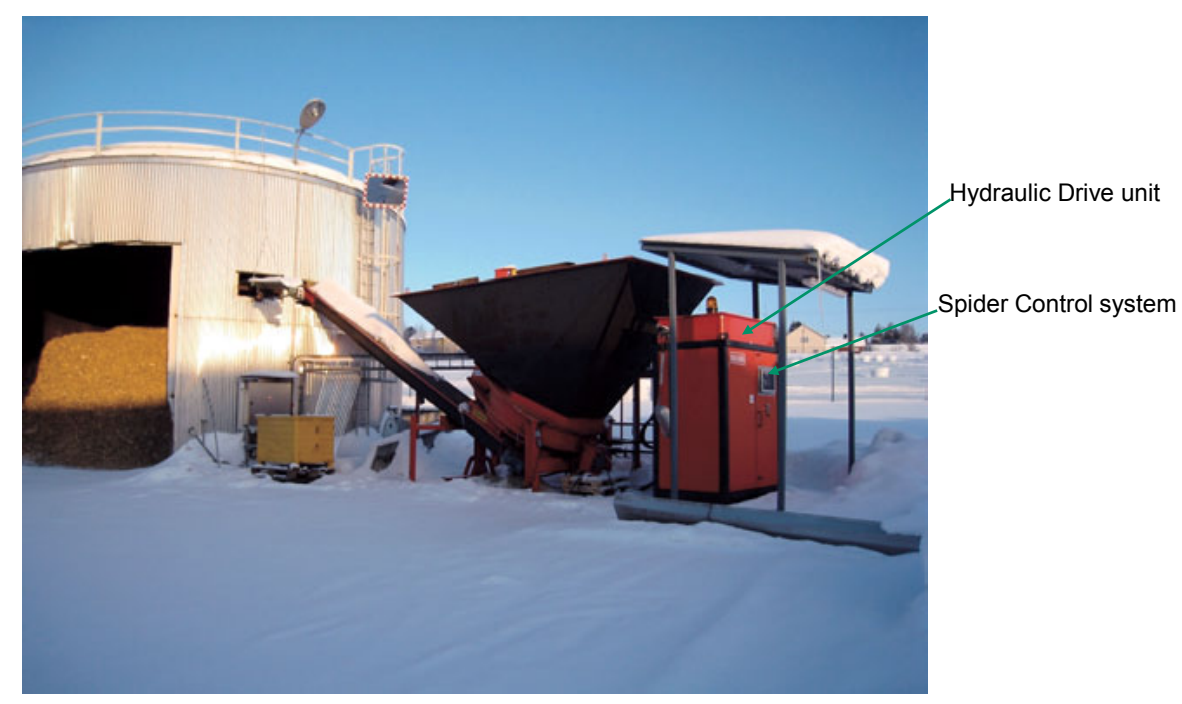

Figure 5. A wood waste shredder at Mellansel plant

The Spider control system contains a unit called, Spider Link, which collects the measured data and provides a serial log channels interface for data download. The collected data are in CSV format and can be transferred via USBmemory or GPRS-link. Figure 6 shows a scenario of data collected from a 
hydraulic drive unit via a spider link and transferred by a GPRS modem to be stored in a log database at the site.

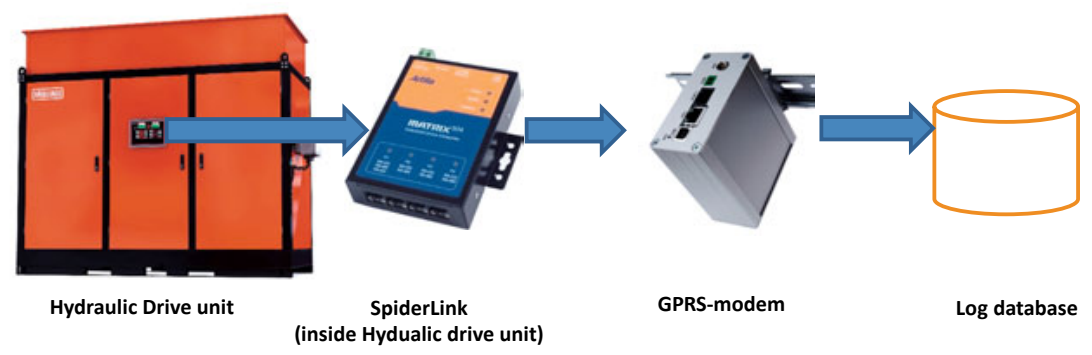

Figure 6. An example of data collection and transportation

Figure 7 shows parts of the inside of a hydraulic drive unit with an electric motor, a hydraulic pump, a heater, a set of filters, etc. To monitor the working status of the hydraulic drive unit, sensors are installed that continuously deliver measured values for the hydraulic drive unit components. While the wood waste shredder is working, sensors are continuously generating data monitoring the equipment. If measured data is not in the desired range of each component it reflects abnormal machine behavior. For example, the hydraulic drive unit may stop working because of too high pressure in its pump. Then experts need to be brought in to analyze the problem and take decisions to avoid an abrupt breakdown.

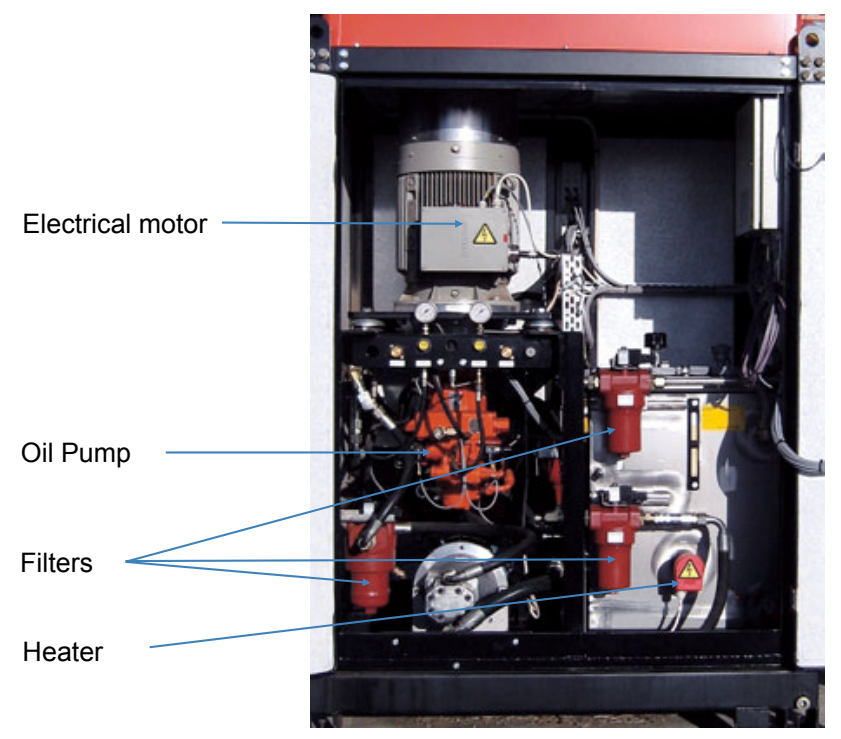

Figure 7. An inside look of a hydraulic drive unit 
One particular goal of FLOQ is to improve the efficiency of the industrial process, for example by reducing the equipment stopping time and managing the maintenance of the machines. This requires analyzing logged sensor readings produced by the equipment to check if it is working normally. The FLOQ ontology provides a universal view of logged sensor data. This enables the test engineer to, e.g., analyze collected historical sensor data to see how long time the components was previously working under certain conditions. Based on these analyses a prediction regarding a component's failure can be estimated and prepared for solutions for equipment outages to make the equipment up and running again. To determine how the equipment has previously behaved in a given situation, the measured values of certain components need to be compared with its expected values. If the result is not within a certain tolerance threshold, it is probably an indication that the component did not function as normal.

In our application scenario, hydraulic drive units are widely distributed and used to supply power to hydraulic motors at each site. To analyze the collected measured data from a hydraulic drive unit, each site maintains its own collected measured data stored in an autonomous log database. Figure 8 shows such a scenario where spider control systems in the hydraulic drive units send measured data through GPRS to a local log database at each site. It allows the head office to analyze the working status of the equipment through the collection of log databases.

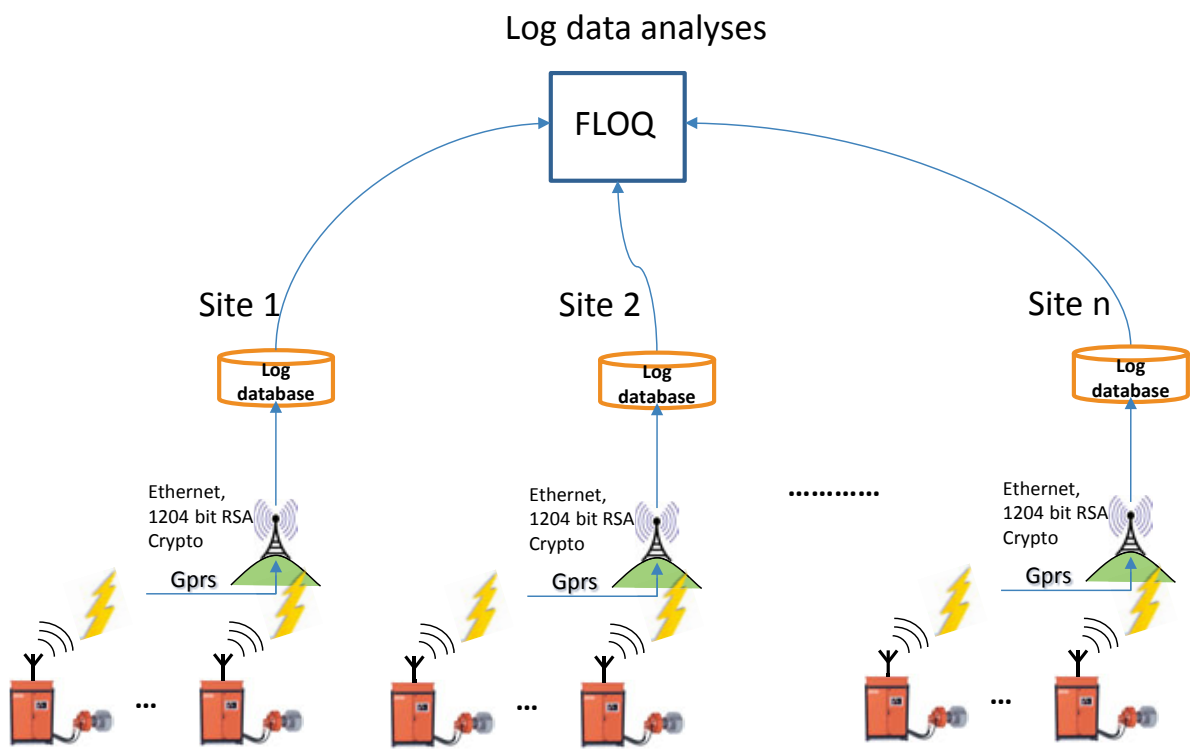

Figure 8. Data collection from distributed equipment at different sites 
To ensure that collected data is useful and reveal abnormalities, the measured data needs to be collected at adequate frequencies. The fault detection and diagnosis on the collected measured data are also based on other factors, such as how the machine is used including operating cycle time, average velocity, etc.

Based on this and similar industrial scenarios [30] the FLOQ ontology was defined to represent meta-data about sensor readings from collections of $\log$ databases.

\subsection{The FLOQ Ontology Definition}

Figure 9 shows basic types and functions representing the FLOQ ontology schema for our industrial application scenario. More properties can be added to customize the ontology.

The type MachineModel represents different kinds of machines. It has four properties represented as stored functions: a unique machine model identifier $m m$ (MachineModel)->Number, a name name(MachineModel)$>$ String, a model description descr(MachineModel)->String, and its manufacturer manuf(MachineModel)->String.

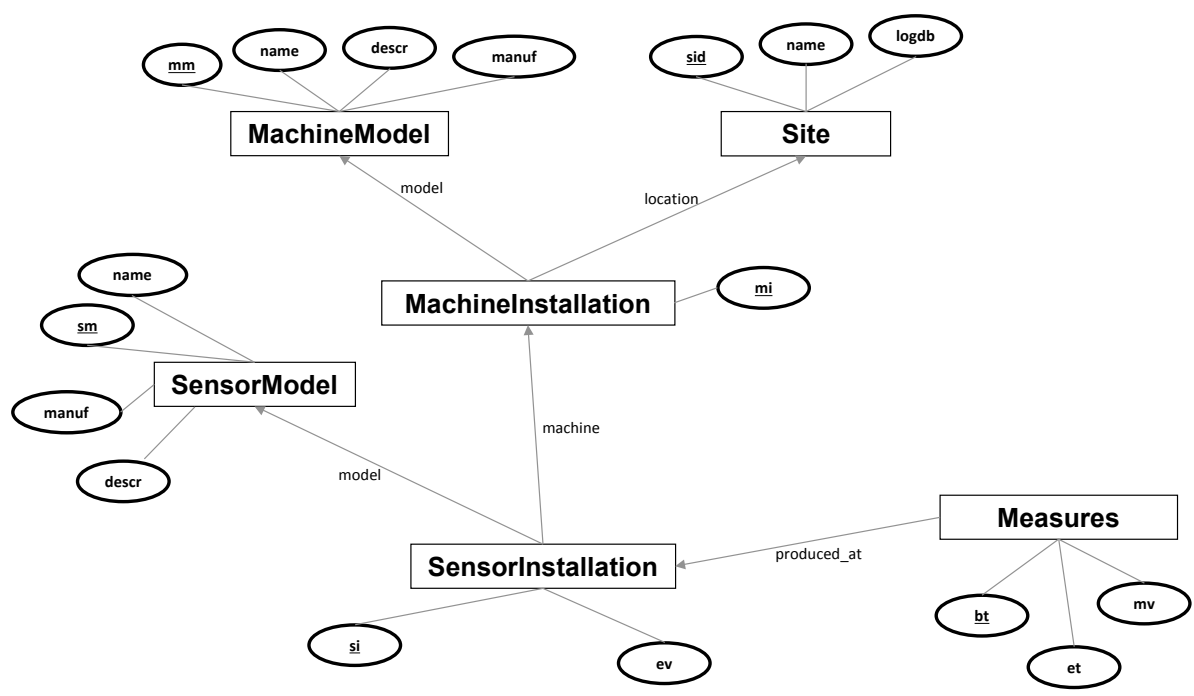

Figure 9. FLOQ ontology schema

The type MachineInstallation represents machine configurations at different sites. It has a unique machine installation identifier mi(MachineInstallation)$>$ Number. The function model(MachineInstallation)->MachineModel identifies the machine model used in an installation and location(MachineInstallation)->Site identifies its site. 
The Site type represents the locations of machines and log databases. It has a unique identifier sid(Site)->Number, a name name(Site)->String, and an identifier of its log database logdb(Site)->Number.

The type SensorModel represents sensor models. Sensor models have the properties: a unique identifier $s m$ (SensorModel)->Number, a name name(SensorModel)->String, a description descr(SensorModel)->String, and a manufacturer manuf(SensorModel)->String.

The type SensorInstallation represents different installations of sensor models. It has a unique identifier si(SensorInstallation)->Number and an expected measured value ev(SensorInstallation)->Number. The sensor model of a sensor installation is identified by the function model(SensorInstallation)->SensorModel, while the machine on which a sensor is installed is identified by the function machine(SensorInstallation)$>$ MachineInstallation.

The Measures type represents measurements from sensors installed on different machines valid in the time interval $[b t$,et). Its attributes include the begin time bt(Measures)->Time, the end time et(Measures)->Time, and the measured value $m v$ (Measures)- $>$ Number. The sensor installation where a value was measured is identified by the function produced_at(Measures)$>$ SensorInstallation.

Figure 10 shows how the FLOQ ontology is represented as an external relational database schema mapped to the FLOQ ontology.

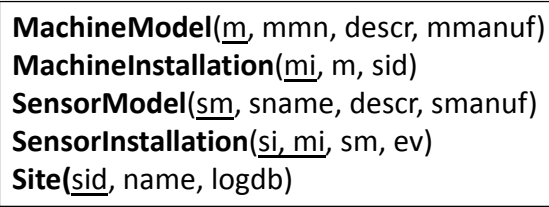

Figure 10. Meta-database schema

Each site has its own autonomous log database table Measures( $m v$ ) (Figure 11) storing measurements from the sensors installed on the machines located at the site.

\section{Measures( $\underline{\mathrm{mi}, \mathrm{si}, \mathrm{bt}}, \mathrm{et}, \mathrm{mv})$}

Figure 11. Log table at each site

The FLOQ view VMeasures (Figure 12) integrates the collection of log databases. It is logically a union-all of all log tables (Measures) on the different sites. In the view the attribute $\log d b$ identifies the origin of a tuple in a log database. Through the meta-database users can make queries over all log tables by joining the meta-data with the view VMeasures. Since the set of 
$\log$ databases is dynamic and accesses many databases it is not feasible to define VMeasures as a static view; instead FLOQ processes queries to VMeasures by dynamically submitting queries to the log databases and collecting the results.

VMeasures(logdb,mi,si,bt,et,mv)

Figure 12. Integrated view in FLOQ server of all log tables

\subsection{Application Scenario Log Data Sets}

As test data in this $\mathrm{PhD}$ project, in the experiments we populate the metadatabase and the log databases with meta-data and log data from Hägglunds. Sensor data was collected from the pump in Figure 7. It contains both normal and abnormal data. The data was delivered as a set of CSV files where each file includes meta-data about the logged data such as unit names, file sequence numbers, measured parameter names, sampling rates, etc., as well as logged sensor readings having a time stamp ts of each measurement. When loading the logged values into a log database, the time stamps are transformed into valid time intervals $[b t, e t$ ) (Figure 11). The data was used in papers II, III, and IV. Figure 13 shows a small sample of log data from the B-side pump pressure sensor in a time interval.

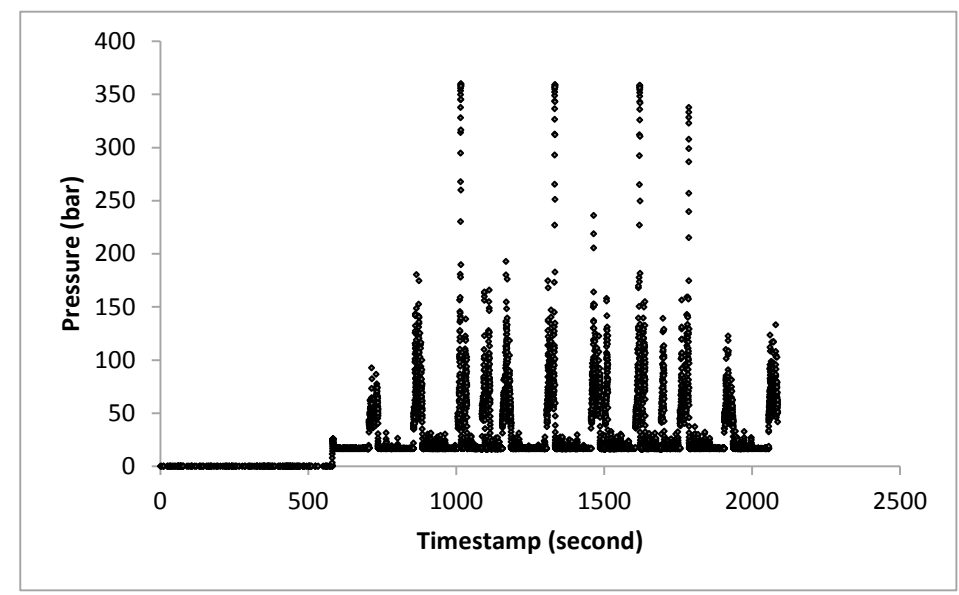

Figure 13. Sampled measured B-side pump pressures

There is an initial warm-up time in the figure of 581.1 seconds. After that, the pressure value starts to climb up and down. Abnormal situations are detected when the measured value $m v$ is larger than the configured expected 
value $e v$. For example, when $e v=359.44$ it means the tolerance is wide and in this case all points are normal. If $e v=0$ all points become abnormal.

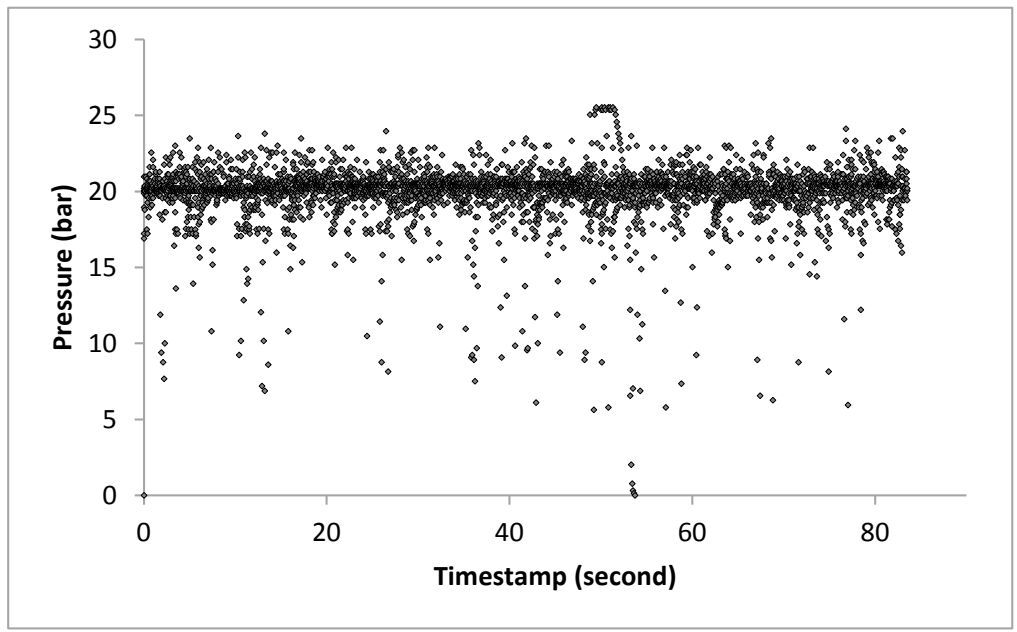

Figure 14. An example of sampled measured data of pressure charge pump

Figure 14 illustrates an example of a scatter plot of the measured values for pressure charge (B-side) of the pump in Figure 7. In this case, the expected value is set to 20.0. Here the threshold value is used to indicate absolute or relative deviation from the expected value. For example, all points in Figure 14 become abnormal when $e v=0$, while all points are normal when $e v=20$. 


\section{The FLOQ System}

\subsection{Architecture}

Figure 15 illustrates the FLOQ architecture. It provides a uniform view of measurement data from a collection of log databases located at different sites. The user specifies queries to the federation in terms of the FLOQ ontology, which is managed by the FLOQ server.

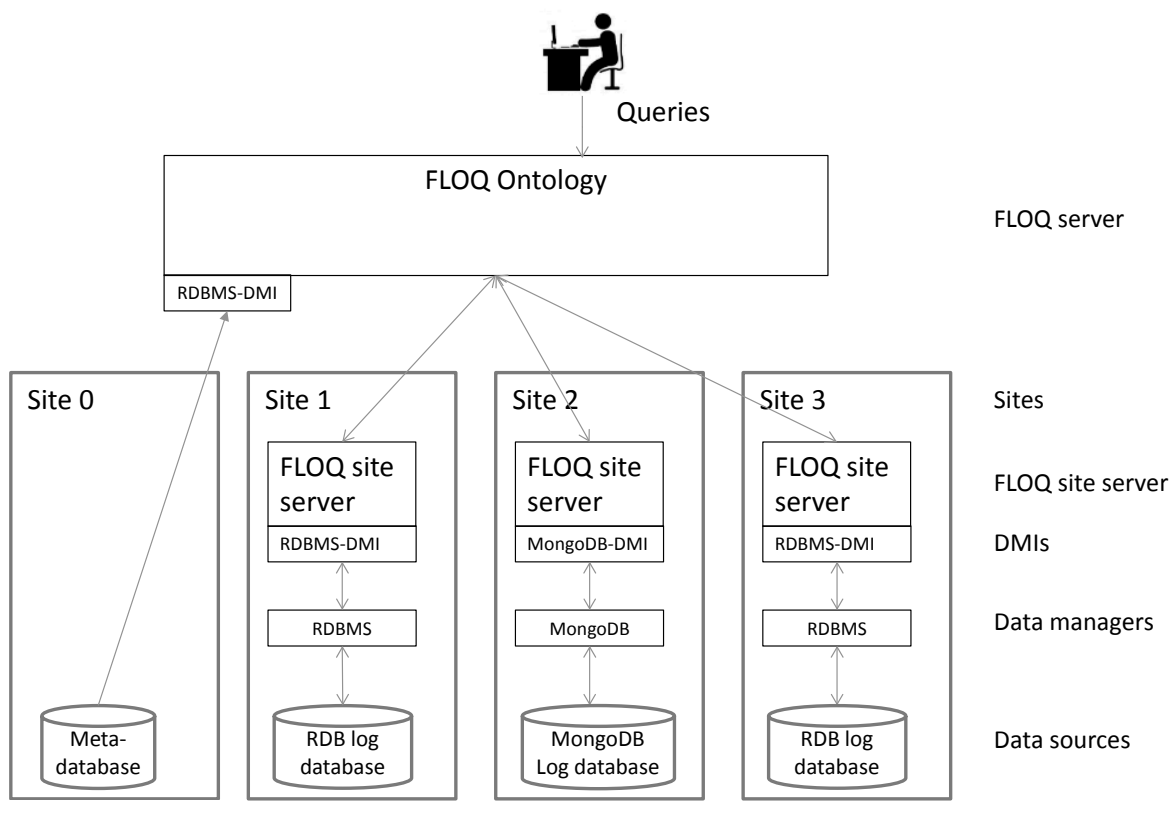

Figure 15. FLOQ system architecture

To enable processing queries over different kinds of data sources managed by different kinds of data managers, FLOQ supports plug-ins of data manager interfaces, $D M I s$, for each kind of data manager. For example, in Figure 15 the $\log$ databases at site one and three are managed by relational data managers, RDBMSs, interfaced using the RDBMS-DMI, while the log database at site two is managed by a MongoDB data manager [25] interfaced through the MongoDB-DMI. Furthermore, parts of the FLOQ ontology itself 
is stored in a relational database at site zero. FLOQ uses the RDBMS-DMI to map the meta-data in site zero to the FLOQ ontology.

To process local queries each site has a FLOQ site server, which is a FLOQ system that contains schema mappings between the log database at the site and the FLOQ ontology view. There is no site server for site zero since the meta-data is mapped directly to the FLOQ ontology and then queried directly from the FLOQ server.

Processing queries joining meta-data in the FLOQ ontology with data from different log databases requires sending sub-queries from the FLOQ server to the corresponding FLOQ site servers. FLOQ processes such joins by accessing the FLOQ ontology to find the identifiers of the log databases that need to be accessed to answer the query. Then sub-queries are generated for each data source and sent to the FLOQ site servers encapsulating them. The query processor in a FLOQ site server translates a received sub-query into a local execution plan that contains calls to its log database through the DMI. It sends back to the FLOQ server the result of executing the query as a stream of tuples. Parallel processing is provided since the FLOQ site servers work independently of each other. The results from many FLOQ site servers are asynchronously merged by FLOQ server while emitting the result to the user.

Figure 16 illustrates meta-data about DMIs stored in the FLOQ ontology. This DMI meta-data enables FLOQ to process queries over different kinds of data managers.

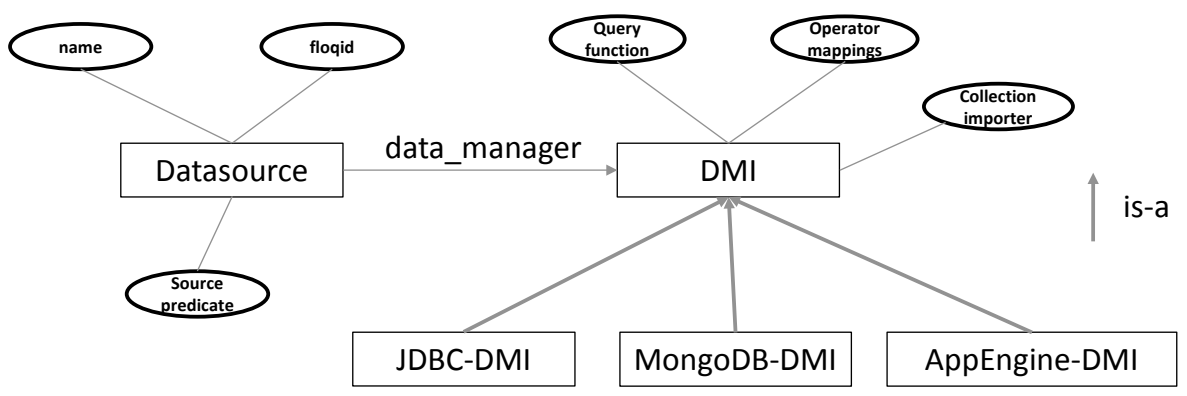

Figure 16. DMI meta-data

Data sources registered with FLOQ are represented by instances of type Datasource. Each data source has a unique name assigned by the user, and a floqid number assigned by FLOQ. The DMI of the system managing a data source is obtained by the function data_manager(). Each data manager provides an interface to execute queries by calling a query function implemented as a foreign FLOQ function. Depending on the capabilities of a data manager its query function can process queries having different query operators mapped to corresponding FLOQ functions through the operator mappings. 
When a new collection in a data source is made accessible to FLOQ the user calls a collection importer to import meta-data of a data source using its data manager. The collection importer generates a source predicate for each accessed data source collection. The source predicate is a derived function that retrieves the tuples in the collection. For example, if the data source represents a log database the tuples represent the rows of the Measures table in Figure 11, while source predicates representing FLOQ meta-data will return the corresponding tuples of the meta-database tables in Figure 10. For a given query to the FLOQ ontology the extensible query processor generates query fragments to different sources by rewriting the source predicates.

The FLOQ ontology stores general meta-information about the locations and names of all FLOQ site servers in the federation, while each FLOQ site server has its own local schema describing its local data source. Distributed FLOQ site servers can be set up communicating using TCP/IP. A FLOQ site server joins the federation by registering itself to the FLOQ server by remotely calling the collection importer in the FLOQ server for the DMI of the site. The collection importer creates a new instance of type Datasource representing the site server along with the source predicate representing the Measures table of the new site. After the registration the FLOQ ontology has all required meta-data about the new FLOQ site server needed to process queries accessing the site server. The FLOQ site servers have full query processors, which enables processing sub-queries submitted from the FLOQ server.

\subsection{FLOQ Query Processor}

The query processor of FLOQ extends the query processor of Amos II in the following ways:

- FLOQ provides novel specialized query processing mechanisms for different kinds of DMIs. The mechanism is based on plug-ins called extractors (named 'absorbers' in Paper I, [40]) and finalizers.

- By developing a DMI for Google App Engine it is possible to store parts of the FLOQ ontology in an external cloud-based datastore. (Paper I, [40])

- A streamed interface to Google App Engine provides queries to Bigtable data repositories returning large data volumes. (Paper I, [40])

- A table driven approach used by the extractors and finalizers provides the NUMTranslator mechanism to translate numerical domain calculus operators into numerical SQL tuple calculus operators. (Paper II, [41])

- The parallel bind-join (PBJ) provides streamed parallel joins between meta-data in the FLOQ ontology and the dynamic set of autonomous, distributed log databases utilizing standard DBMS APIs. (Paper III, [42]) 
- The parallel bulk-load join (PBLJ) utilized the bulk load capabilities of a site data manager to provide scalable joins between the meta-database and the log databases. (Paper III, [42])

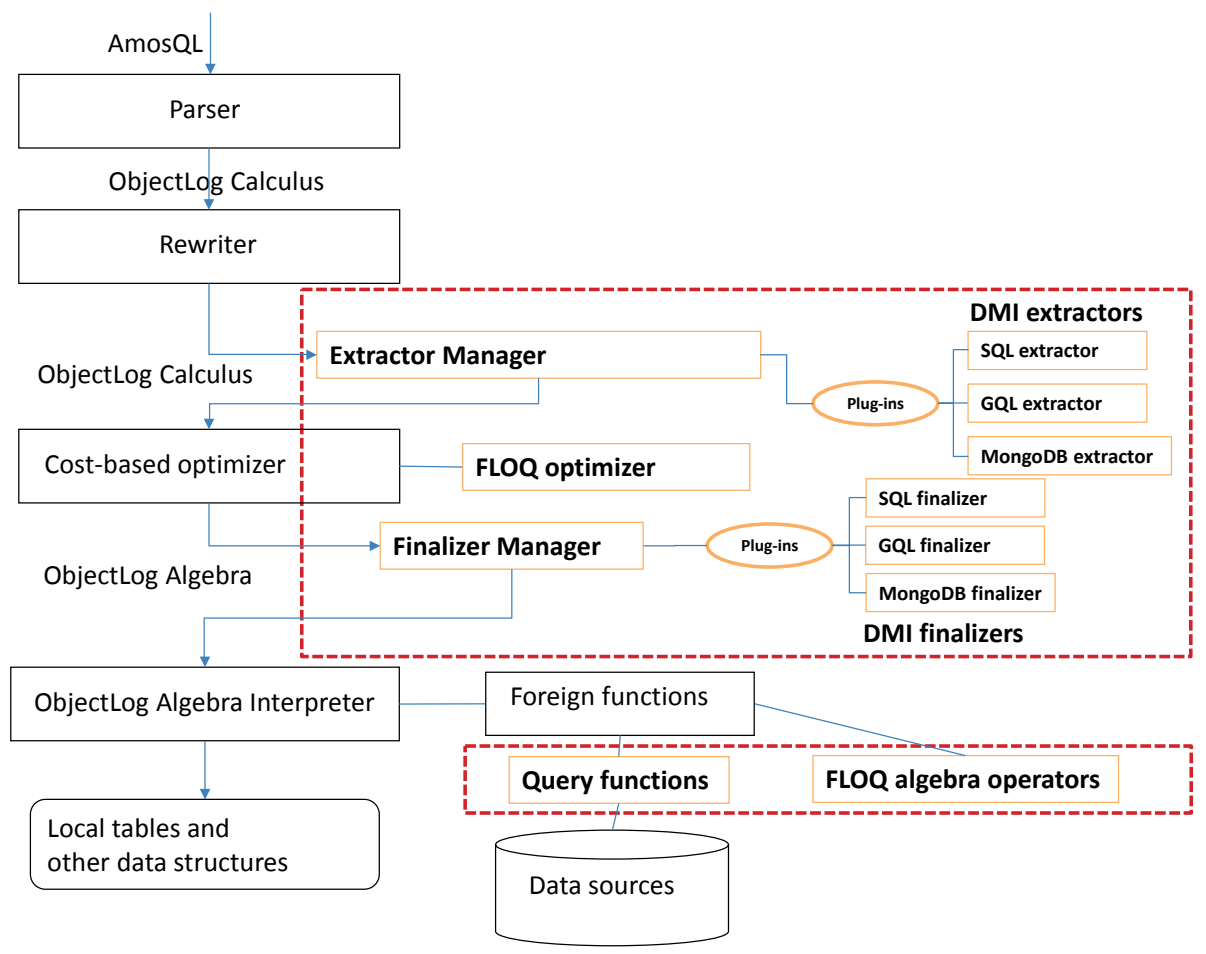

Figure 17. FLOQ query processor extensions of the Amos II query processor

Figure 17 illustrates how FLOQ extends the query processing steps of Amos II. The extensions are highlighted by the dot-lined rectangles in the figure. The following modules are added:

1. The ObjectLog rewriter of Amos II is extended with an extractor manager that automatically transforms ObjectLog calculus fragments into sub-queries accessing the different kinds of data sources. For each DMI there is a specialized DMI extractor plugged-into the extractor manager. The extractor manager takes an ObjectLog query and, for each source predicate referenced in the query, calls the corresponding DMI extractor to collect from the query the predicates that can be executed by the site server, based on the capabilities of the DMI (paper I, [40]).

2. After the cost-based optimization the execution plan is passed to the finalizer manager. It traverses the optimized ObjectLog algebra expression to translate algebra fragments into calls to the query function of the DMIs used to access queried data sources. As for the extractors, each DMI has a specialized DMI finalizer plugged-into the finalizer manager. A DMI finalizer transforms into query function calls the fragments of an 
algebra expression that can be translated based on the query capabilities of the DMI's data manager. For example, for translating numerical ObjectLog algebra expressions to SQL, the NUMTranslator algorithm transforms numerical ObjectLog algebra operators into SQL tuple calculus expressions through the operator mappings table of FLOQ in Figure 16. The fragments of an ObjectLog algebra expression that cannot be translated into query function calls remain in the FLOQ algebra expression. Thus the rewritten query plan will be an ObjectLog algebra expression with calls to query functions (paper II, [41]).

3. To speed up queries combining meta-data with distributed logged sensor readings, sub-queries to the log databases should be run in parallel. Two join strategies PBJ and PBLJ for parallel execution of queries joining meta-data with data from autonomous log databases using standard DBMS APIs are proposed and their performance evaluation are analyzed (Paper III, [42]). In general, PBLJ performs better than PBJ, details in [42]. To implement PBJ and PBLJ, the FLOQ optimizer (Figure 17) was developed. It rewrites queries to the VMeasures view (Figure 12) to generate calls to FLOQ algebra operators, using PBJ or PBLJ to enable parallel sub-queries to the $\log$ databases. The extractor and finalizer plug-ins of a RDBMS or MongoDB (Figure 17) are utilized by the FLOQ optimizer to generate corresponding sub-queries to RDBs or MongoDB log databases, respectively.

4. It was investigated of how the state-of-the-art NoSQL DBMS MongoDB was suitable as a scalable log database manager. The performance of using MongoDB to store the Measures tables at a site (Figure 11) was compared with using two different relational DBMSs with various configurations. MongoDB was shown to have similar performance as a state-of-art RDBMS (Paper IV, [23]). A MongoDB query function interface was developed [22] along with a MongoDB extractor and finalizer plug-ins (Figure 17). 


\section{Technical Contributions}

The technical contributions of this Thesis are summarized below, together with summaries of the published papers to guide the reader on how the included papers relate to the research questions.

\subsection{Paper I}

Zhu, M., Risch, T. (2011) Querying Combined Cloud-Based and Relational Databases, The 2011 International Workshop on Data Cloud (D-CLOUD 2011), at 2011 International Conference on Cloud and Service Computing (CSC), Hong Kong, China, December 12-14, 2011, In Proc. CSC 2011, pp. 330-335.

\subsubsection{Summary}

An increasing amount of data is stored in cloud repositories, which provide high availability, accessibility, and scalability. The paper investigates the possibility to store and query part of the FLOQ ontology in a cloud based storage, Google Bigtable [7]. To interface Bigtable, a DMI for the Google App Engine [13] was developed to access FLOQ ontology elements stored in a Bigtable repository. To compensate for the limited query capabilities of the GQL [34], the query language of Google App Engine, novel specialized query processing mechanism based on plug-ins called absorbers (later renamed to extractors) and finalizers were developed. Furthermore, a streamed communication protocol provides queries to Bigtable returning large data volumes.

Paper I answers research question three and partly answers research question two.

I am the primary author of this paper. The other authors contributed to discussion and paper writing.

\subsection{Paper II}

Zhu, M., Stefanova, S., Truong, T., Risch, T. (2014) Scalable Numerical SPARQL Queries over Relational Databases, 4th International workshop on 
linked web data management (LWDM 2014) in conjunction with the EDBT/ICDT 2014 Joint Conference, Athens, Greece, March 28, 2014, In Proc. LWDM 2014, pp. 257-262.

\subsubsection{Summary}

The paper investigates the problem of detecting past machine anomalies by querying historical sensor readings stored in a relational database. Typically anomaly detection queries include numerical expressions, inequalities, string matching, and set membership tests inside query conditions. We call such queries numerical queries. For scalable execution of numerical queries, numerical operators should be pushed into SQL rather than executed as postprocessing filters outside the RDB; otherwise the query execution is slowed down since a lot of data is transported back from the RDB server before the filtering. In addition indexes on the server are not utilized.

The paper presents the NUMTranslator algorithm, which transforms numerical and other domain calculus operators into corresponding SQL expressions. The experiments show that NUMTranslator substantially improves the query performance in particular when the numerical expressions inside query conditions are highly selective. The algorithm uses a table driven approach to translate numerical domain calculus expressions into corresponding numerical SQL expressions. We compared the performance of the numerical queries with and without applying NUMTranslator. We also compared our approach with other systems. In the paper the query language SPARQL was used rather than SQL, showing the FLOQ can process different query languages. Only D2RQ [3] could execute numerical SPARQL queries over RDBs, but substantially slower, since D2RQ does not employ an approach similar to NUMTranslator.

Paper II answers research question five.

I am the primary author of this paper, while the other authors contributed with discussions and paper writing. Silvia Stefanova helped with related work while Thanh Truong contributed with some initial implementation work.

\subsection{Paper III}

Zhu, M., Mahmood, K., Risch, T. (2015) Scalable Queries Over Log Database Collections, 30th British International Conference on Databases (BICOD 2015), Edinburgh, UK, July 6-8, 2015, In Proc. BICOD 2015, pp. $173-$ 185. 


\subsubsection{Summary}

Two new join strategies are proposed, parallel bind-join (PBJ) and parallel bulk-load join (PBLJ), for parallel execution of queries joining meta-data with data from autonomous databases using standard DBMS APIs. A cost model is proposed to guide and evaluate the efficiency of the join strategies. The performance of the two methods is evaluated using data from a realworld application [30], where sensor readings are collected from machines at distributed sites and joined through the FLOQ meta-database at a central site in order to detect unexpected behaviors. For the performance evaluation we define typical fundamental queries to detect anomalies and investigate the impact of our join strategies guided by the cost model. The experimental results validate the cost model. In general, PBLJ performs better than PBJ when the number of bindings from the meta-database is increased and the number of result tuples is small.

Paper III answers research question four and partly answers research question two.

I am the primary author of this paper, while the co-authors helped with discussions and paper writing. Khalid Mahmood contributed to the costmodel for join strategies.

\subsection{Paper IV}

Mahmood, K., Risch, T., Zhu, M. (2015) Utilizing a NoSQL Data Store for Scalable Log Analysis, 19th International Database Engineering \& Applications Symposium (IDEAS 2015), Yokohama, Japan, July 13-15, 2015, In Proc. IDEAS 2015, pp. 49-55.

\subsubsection{Summary}

A potential problem for persisting large volume of data logs with a conventional relational database is that loading massive logs produced at high rates is not fast enough due to the strong consistency model and high cost of indexing. As a possible alternative, a modern NoSQL data store, which sacrifices transactional consistency to achieve higher performance and scalability, can be utilized. In this paper, we investigate to what degree a state-of-the-art NoSQL database can achieve high performance persisting and fundamental numerical queries to analyze data in log databases. For the evaluation, a state of-the-art NoSQL database, MongoDB, is compared with a relational DBMS from a major commercial vendor and with a popular open source relational DBMS. MongoDB is chosen as it provides both primary and secondary indexing needed for anomaly detection, which is essential for scalable processing of queries over large log databases. Our results reveal that relaxing 
the consistency does not provide substantial performance enhancement for any of the systems. For high-performance loading of data logs MongoDB is shown to have similar performance as a state-of-the-art relational database, while the query performance of the relational database is usually better.

The main contribution of the paper is a performance evaluation of persisting and analyzing data logs under different consistency configurations, as needed by log databases.

Paper IV partly answers research question two.

I contributed to discussion, reviewed, and proposed changes in the paper writing. 


\section{Conclusions and Future work}

In this Ph.D. project, I started investigating querying data stored in a cloud data store with limited query capabilities compared to a regular relational database. I developed the BigIntegrator system to enable queries combining data from a cloud data store with regular relational databases. The architecture of the system included novel query processing mechanisms based on plug-ins called extractors and finalizers, which must be implemented for each new data manager. The extensions compensate for limited query capabilities of different data managers. Furthermore, due to the quota limitation in transferring data from a cloud data store per request, a streamed communication interface was implemented to enable queries returning big volume of data.

In order to analyze passed behavior of monitored equipment, sensor readings can be stored in relational databases and analyzed with queries. However, queries for machine anomaly detection often involve numerical expressions inside query conditions. The continuation of BigIntegrator, i.e. the FLOQ system, is able to process in a scalable way numerical queries that analyze logged data stored in collections of different kinds of databases.

To efficiently process numerical queries over log databases, the NUMTranslator algorithm was developed, which extracts and translates numerical domain calculus expressions into corresponding numerical SQL expressions by using a table driven approach. The approach was evaluated on a benchmark scenario in an industrial setting where logged data stored in a relational database was analyzed using numerical queries. The experiments show that NUMTranslator substantially improves the query performance of numerical queries, in particular when the numerical expressions inside query conditions are highly selective.

To process queries over geographically distributed log databases, I developed two new join strategies, parallel bind-join (PBJ) and parallel bulk-load join (PBLJ). For the performance evaluation I defined typical fundamental queries and investigated the impact of the join strategies. A cost model was used to guide and evaluate the efficiency of the strategies. The experimental results validated the cost model. In general, PBLJ performs better than PBJ when the number of bindings from the meta-database is increased and the returned result is small.

Finally, it was shown that a NoSQL data store such as MongoDB is a suitable alternative to relational databases for storing log databases. Based 
on this, a MongoDB-DMI [22] was developed to enable FLOQ queries combining logged data stored in MongoDB databases with other data sources.

As future work, the system should be extended to handle new kinds of data sources by developing new DMIs, for example, DMIs to call MapReduce systems [10] that process large data logs as parallel batch jobs. Furthermore, logged data should be combined with streaming data to match on-line data from equipment with historical data in log databases in order to identify how similar situations were previously handled when anomalies are detected in streaming data. To handle expensive analyses over streaming and stale data novel parallel query processing strategies such as parasplit [39] can be utilized.

In the experiments a rather small set of autonomous log databases were used. The impact of having a very large number of log databases should be further investigated. Different strategies to improve communication overheads, e.g. by compression, should be investigated.

Extensible indexing techniques can be used for improving the performance of complex numerical queries over logs [35] [36]. 


\section{Summary in Swedish}

Modern produktutveckling genererar stora mängder data under alla dess olika faser, från utveckling och tillverkning, genom användning och underhåll, till vidareutveckling och återvinning. Det är mycket viktigt att kunna lagra, söka och analysera de olika slags data som genereras under produktcykeln för att skapa högkvalitativa och tillförlitliga produkter. Det behövs även metoder för att samla ihop, bearbeta och analysera producerade data.

Avhandlingen är baserad på ett reellt industriellt scenario [30] där maskiner, t.ex. hjullastare, hydrauliska pumpar, eller skärverktyg är spridda över olika anläggningar vid olika geografiska platser och där sensorer på maskinerna producerar stora volymer mätvärden. De data som generas vid varje anläggning representerar tidsstämplade sensorvärden från olika maskinkomponenter (t.ex. oljetemperatur eller tryck) och lagras i lokala loggdatabaser vid anläggningen. Dessutom behövs ett effektivt sätt att övervaka och validera att övervakad utrustning fungerar som avsett. Loggdatabaserna används för att finna och analysera onormalt beteende hos de övervakade maskinerna på de geografiskt distribuerade anläggningarna. Samlingen av loggdatabaser är vidare dynamisk i den meningen att nya anläggningar tillkommer och försvinner över tiden.

För att kunna analysera och jämföra data från loggdatabaserna behövs en övergripande s.k. meta-databas som beskriver egenskaper hos övervakad utrustning och dess loggdatabaser, t.ex. olika maskinkonfigurationer vid anläggningarna, vilka typer av sensormodeller som är installerade på de olika maskinerna och vilka toleranser som är aktuella. Meta-databasen tillhandahåller en global vy av tillståndet hos alla maskiner vid alla anläggningar. Genom meta-databasen kan man ställa frågor som spänner över loggdatabaserna och identifierar när övervakade maskiner uppträder eller har uppträtt onormalt. En speciell utmaning som behandlas $i$ avhandlingen är skalbar hantering av frågor som kombinerar data $\mathrm{i}$ den övergripande meta-databasen med data från de distribuerade loggdatabaserna.

Ett onormalt beteende hos maskiner kan ofta upptäckas genom att identifiera onormala avvikelser i uppmätta värden som lagrats i loggdatabaserna. Sådana avvikelser kan uttryckas som databasfrågor innehållande numeriska villkor, exempelvis att sensorvärden avviker utanför toleransmarginalen för en viss sensormodell under en viss sammanhängande tidsperiod. Detta kräver att systemet kan utföra numeriska frågor över en mängd av loggdatabaser 
beskrivna av en meta-databas som innehåller exempelvis dessa toleranser och information om aktuella typer av maskiner.

Följande forskningsfrågeställningar undersöks i avhandlingen:

1. Den övergripande forskningsfrågan är: Hur representerar man en meta-databas som beskriver distribuerad industriell utrustning och dess loggdatabaser?

2. Hur kan olika sorters mjukvara för att hantera databaser användas för lagring av både loggdatabaserna och meta-databasen?

3. Hur kan moln-baserad datalagring användas för att representera meta-databasen?

4. Hur kan systemet effektivt och skalbart utföra frågor som kombinerar meta-databasen med data från de distribuerade loggdatabaserna?

5. Hur kan systemet effektivt utföra numeriska frågor som identifierar onormala mätvärden i loggdatabaserna?

Som en ansats för dessa utmaningar och för att besvara den första forskningsfrågan har vi utvecklat ett system, FLOQ (Fused Log database Query processor) illustrerat i Figur 18. FLOQ integrerar samlingar av dynamiska, distribuerade och separata loggdatabaser genom en övergripande metadatabas som kallas FLOQ-ontologin. FLOQ-ontologin hanteras av ett system som kallas FLOQ-servern.

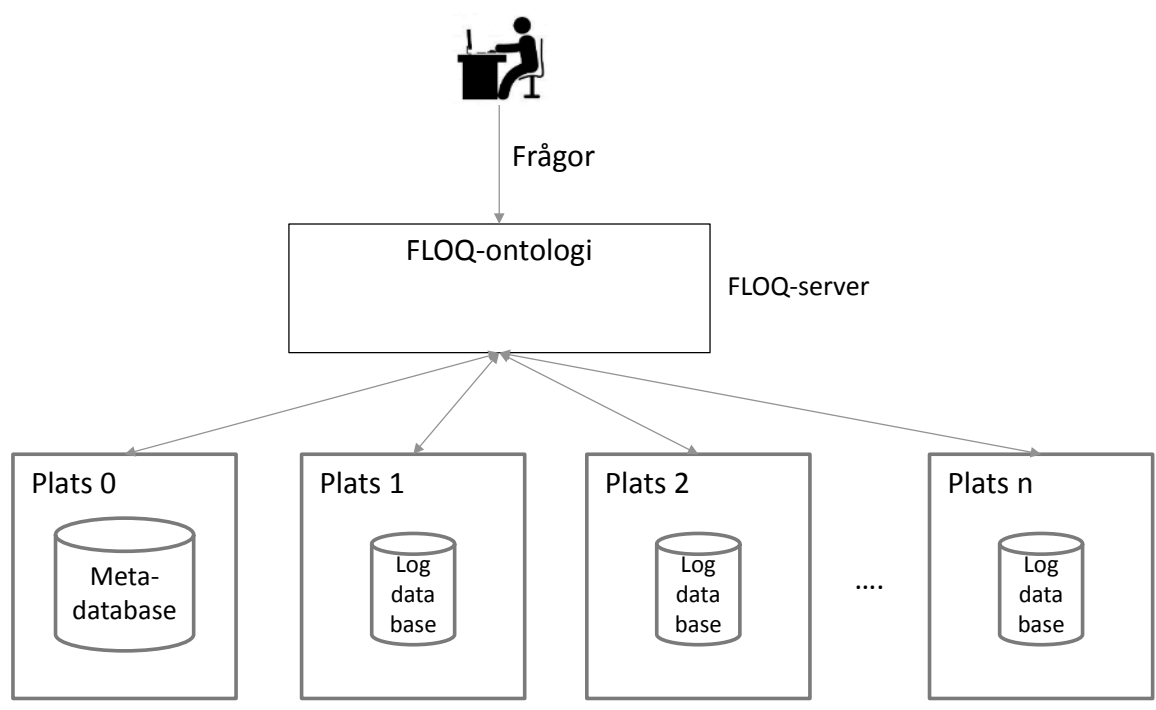

Figur 18. FLOQ-översikt

FLOQ-ontologin beskriver meta-data och fysiska egenskaper hos industriell utrustning på geografiskt distribuerade anläggningar. FLOQ-ontologin är generell och kan beskriva olika sorters industriell utrustning. Varje anläggning på plats $1,2, \ldots, \mathrm{n}$ har utrustning som producerar mätvärden från givare lagrade i separata loggdatabaser. De olika loggdatabaserna underhålls lokalt 
per anläggning oberoende av andra databaser. FLOQ-ontologin inkluderar beskrivningar av dessa loggdatabaser. Även delar av FLOQ-ontologin kan lagras i en extern meta-databas som finns på plats 0 . Användaren sänder frågor till FLOQ-servern för att söka i loggdatabaserna och i metadatabasen. Frågorna formuleras i termer av FLOQ-ontologin. De analyserar ofta data i loggdatabaserna för att upptäcka onormala avvikelser i lagrade mätvärden. Sådana frågor innehåller ofta numeriska villkor, t.ex. för att identifiera onormalt stora skillnader mellan uppmätta och förväntade givarvärden.

FLOQ-ontologin är representerad i en generell datamodell som kan beskriva alla sorters meta-data. Vidare kan både meta-databasen och loggdatabaserna lagras i olika format m.h.a. olika sorters databashanterare. De olika externa datarepresentationerna är avbildade till FLOQ-ontologin. FLOQ tillhandahåller en generell och utbyggbar mekanism för effektivt utförande av frågor över olika sorters databaser, som t.ex. MySQL eller MongoDB [22][25]. Detta ger ett svar på den andra forskningsfrågan.

För att göra delar av FLOQ-ontologin globalt tillgängligt för världsomspännande organisationer tillåter FLOQ att en del av ontologin lagras i en extern moln-databas som Googles Bigtable [7]. Sådana moln-databaser tillhandahåller hög universell tillgänglighet och skalbarhet. FLOQ gör det möjligt att avbilda extern datarepresentation i Bigtable eller andra datarepresentationer till FLOQ-ontologin [40]. Meta-data kan såldes lagras antingen direkt i FLOQ-ontologins datamodell, i en relationsdatabas, eller i en molndatabas som Bigtable. Denna möjlighet av FLOQ att representera ontologin på olika sätt besvarar forskningsfråga tre.

FLOQ tillhandahåller ett delsystem för att effektivt och skalbart utföra databasfrågor över distribuerade loggdatabaser i termer av FLOQ-ontologin. En mekanism för att modulärt plugga in beskrivningar av olika sorters databashanterare gör det möjligt för systemet att automatiskt dela upp en fråga till FLOQ-ontologin i separata delfrågor som sänds till de distribuerade loggdatabaserna. Två olika strategier förslås för att dela upp frågor som kombinerar meta-data i ontologin med data i loggdatabaserna, parallel bindjoin (PBJ) och parallel bulk-load join (PBLJ) [42]. Denna frågebearbetning över distribuerade loggdatabassamlingar besvarar forskningsfråga fyra.

Skalbar bearbetning av numeriska frågor över loggdatabaser representerade som relationsdatabaser (t.ex. MySQL eller Oracle) kräver att numeriska villkor i största möjligaste mån utförs som lokala SQL-frågor direkt över de olika loggdatabaserna snarare än att data transporteras till FLOQ-servern för filtrering där. NUMTranslator algoritmen [41] konverterar numeriska uttryck i termer av meta-databasmodellen till motsvarade SQL-frågor. I [41] visas att NUMTranslator förbättrar prestanda väsentligt baserat på frågor som identifierar avvikelser i loggdatabaser lagrade i en relationsdatabas. Detta besvarar forskningsfråga fem. 


\section{Acknowledgements}

First I would like to thank Professor Tore Risch, you as my main supervisor is most influential to my research project. Thanks for giving me this opportunity to do research in database technology. When given the opportunity, I started my PhD journey in database research. During these years, I have learned a lot coding and system development skills from you. Of course, writing scientific research papers is something new to me at the beginning. But, I have improved a lot during these years, working as a PhD student. Thank you. I would also like to thank the former and current UDBL members, Kjell Orsborn, Erik Zeitler, Manivasakan Sabesan, Silvia Stefanova, Lars Melander, Cheng Xu, Andrej Andrejev, Thanh Truong, Mikael Lax, Sobhan Badiozamany, and Khalid Mahmood. I would like to thank Kjell Orsborn for helping me in the $\mathrm{PhD}$ Thesis. Thanks Silvia Stefanova for your help and supervision. I have been roommate with Lars and Andrej and like the time we have been sharing office. Thank you Lars for helping me drive car, buy and transport the furniture when I needed to settle down with my life in Uppsala. Thanks Cheng, I enjoyed talking to you and thanks for your help, especially when I was in some urgent situation. Thanks Thanh, I came to the group a year earlier than you, but slowly I realized we share the most similar view on some aspects, which are not usually analyzed. For political discussion, I was most of the time quiet and try to keep the conversation short. Thanks for the conversation we had and I appreciate it very much. Thanks Mikael for the help and discussion. Thanks Sobhan for the discussion and having lunches together. Thanks Khalid for help and discussion in research and the jokes that made me laugh so much. Thanks for friendship from all you guys. Thanks for the advices given during these years in research or even beyond research. These advices are very good and have helped me a lot in my $\mathrm{PhD}$ journey. Thanks for listening to me especially when I had problems in research and felt a bit down.

I would like to thank my friend Jun He. We used to work in the same floor in ICT building 1. Thanks for being soul mate and nice friend to me. I enjoyed so much to talk with you and shared my happiness and sadness. I like your family as well. I appreciate the friendship very much.

I would like to thank Matteo Magnani. I enjoyed the Italian food and had lot of fun in the parties. I like your family as well. 
I would like to thank Ulrika Andersson. Thank you for helping me in the issues while living in Sweden. I also thank you for your advices. I also like to thank Anne-Marie Jalstrand and Anna-Lena Forsberg for your help.

Of course, there are a lot of friends and hard to write about everyone here. But I would like to thank you all, thanks for the time having fun with you guys.

For my parents, I would like to credit them with huge gratitude. It was in November 2003 I started the journey of studying and living in abroad. That was the first time I had lived apart from you outside of China and it was such a long distance from you. Without support at the beginning, it might have been impossible for me to continue my journey until today. This journey really changed the track of my life and thanks to my parents supporting me all the time no matter whether I was up or down. Thank you for your love and care. I love you so much and can't express my love to you in words. You and my future family are the most important part in my life.

I would like to thank myself as well, for being persistent and consistent in going through the journey that started in November 2003. I have really learned a lot in research and beyond. It is a unique and beneficial experience that I got from this journey.

Minpeng Zhu 


\section{Bibliography}

1. Andrejev, A., Risch, T.: Scientific SPARQL: Semantic Web Queries over Scientific Data. In: DESWEB workshop, pp. 5-10 (2012)

2. Andrejev, A., Toor, S., Hellander, A., Holmgren, S., Risch, T.: Scientific Analysis by Queries in Extended SPARQL over a Scalable e-Science Data Store. In: eScience, pp. 98-106 (2013)

3. Bizer, C., Cyganiak, R., Garbers, G., Maresch, O., Becker, C.: The D2RQ Platform v0.7 - Treating Non-RDF Relational Databases as Virtual RDF Graph, http://www4.wiwiss.fu-berlin.de/bizer/d2rq/spec/

4. Brettel, M., Friederichsen, N., Keller, M., Rosenberg, M.: How Virtualization, Decentralization and Network Building Change the Manufacturing Landscape: An Industry 4.0 Perspective. J. International Journal of Mechanical, Aerospace, Industrial, Mechatronic and Manufacturing Engineering. 8(1), 37-44 (2014)

5. Cassandra, http://cassandra.apache.org/

6. Cattell, R.: Scalable SQL and NoSQL data stores. J. ACM SIGMOD Record. 39(4):12-27, 2010

7. Chang, F., et al.: Bigtable: A distributed storage system for structured data. In: OSDI, pp. 205-218 (2006)

8. Codd, E. F.: Relational completeness of database sublanguages. J. Communications of the ACM. 13(6):377-387, 1970

9. CouchDB, http://couchdb.apache.org/

10. Dean, J., Ghemawat, S.: MapReduce: Simplified Data Processing on Large Clusters. In: OSDI, pp. 107-113 (2004)

11. Garcia-Molina, H., Ullman, J.D., Widom, J.: Database Systems: The Complete Book. Prentice Hall, Upper Saddle River, NJ, USA (2009)

12. Graefe, G.: Query evaluation techniques for large databases. J. ACM Computing Surveys (CSUR). 25(2):73-169, 1993

13. Google App Engine, http://code.google.com/appengine/docs/whatisgoogleappengine.html

14. Haas, L., Kossmann, D., Wimmers, E., Yang, J.: Optimizing queries across diverse data source. In: VLDB, pp. 276-285 (1997)

15. Hansson, M.: Wrapping External Data by Query Transformations, Master Thesis, Computer. Science no. 260, ISSN 1100-1836, Uppsala University (2003)

16. HBase, http://hbase.apache.org/

17. Hägglunds, http://www.boschrexroth.com/en/xc/company/haegglundslandingpage/haegglunds-landingpage 
18. Hägglunds direct drive system,

http://dc-america.resource.bosch.com/media/us/press_kits_1/workboat/ brochures_1/Rexroth-Hagglunds-Drive-Systems.pdf

19. Industrial Internet: Pushing the boundaries of minds and machines, http://www.ge.com/docs/chapters/Industrial_Internet.pdf

20. Lee, J., Bagheri, B., Kao, H. -A.: A Cyber-Physical Systems architecture for Industry 4.0-based manufacturing system. J. Manufacturing Letters. 3: 18-23, 2015

21. Made in China 2025, http://csis.org/publication/made-china-2025

22. Mahmood, K.: Scalable Persisting and Querying of Streaming Data by Utilizing a NoSQL Data Store, Master Thesis IT 14 021, Department of Information Technology, Uppsala University (2014) http://www.it.uu.se/research/group/udbl/Theses/KhalidMahmoodMSc.pdf

23. Mahmood, K., Risch, T., Zhu, M.: Utilizing a NoSQL Data Store for Scalable Log Analysis. In: IDEAS, pp. 49-55 (2015)

24. Memcached, http://www.memcached.org/

25. MongoDB, http://docs.mongodb.org/

26. Pavlo, A., Paulson, E., Rasin, A., Abadi, D.J., Dewitt, D.J., Madden, S., Stonebraker, M.: A Comparison of Approaches to Large-Scale Data Analysis. In: SIGMOD, pp. 165-178 (2009)

27. Redis, http://redis.io/

28. Risch, T., Josifovski, V., Katchaounov, T.: Functional data integration in a distributed mediator system. In: Gray, P.M.D., Kerschberg, L., King, P.J.H., Poulovassilis, A. (eds.): The Functional Approach to Data Management - Modeling, Analyzing, and Integrating Heterogeneous Data. pp. 211-238. Springer, Verlag (2004)

29. Shoshani, A., Rotem, D.: Scientific Data Management: Challenges, Technology, and Deployment. Taylor and Francis Group, Boca Raton, FL, USA (2009)

30. Smart Vortex Project, http://www.smartvortex.eu/

31. Snodgrass, R.T.: Temporal databases. In: Frank, A.U., Campari, I., Formentini, U. (eds.): Theories and Methods of Spatio-Temporal Reasoning in Geographic Space. vol. 639, pp. 22-64. Springer, Verlag (1992)

32. Stonebraker, M.: SQL databases v. NoSQL databases. J. Communications of the ACM. 53(4):10-11, 2010

33. SPARQL 1.1 Query Language, https://www.w3.org/TR/sparql11-query/

34. The GQL reference web page, http://code.google.com/appengine/docs/python/datastore/gqlreference.html

35. Truong, T., Risch, T.: Scalable Numerical Queries by Algebraic Inequality Transformations. In: DASFAA, pp. 95-109 (2014)

36. Truong, T., Risch, T.: Transparent inclusion, utilization, and validation of main memory domain indexes. In: SSDBM, Article No. 21 (2015) $\mathrm{DOI}=10.1145 / 2791347.2791375$

37. Özsu, M.T., Valduriez, P.: Principles of Distributed Database Systems. Springer Science+Business Media, New York (2011) 
38. Xu, C., Wedlund, D., Helgoson, M., Risch, T.: Model-based Validation of Streaming Data. In: DEBS, pp. 107-114 (2013)

39. Zeitler, E., Risch, T.: Massive scale-out of expensive continuous queries. J. ACM VLDB. 4(11):1181-1188, 2011

40. Zhu, M., Risch, T.: Querying combined cloud-based and relational databases. In: CSC, pp. 330-335 (2011)

41. Zhu, M., Stefanova, S., Truong, T., Risch, T.: Scalable Numerical SPARQL Queries over Relational Databases. In: LWDM workshop, pp. 257-262 (2014)

42. Zhu, M., Mahmood, K., Risch, T.: Scalable Queries Over Log Database Collections. In: BICOD, pp. 173-185 (2015) 


\section{Acta Universitatis Upsaliensis}

Digital Comprehensive Summaries of Uppsala Dissertations from the Faculty of Science and Technology 1343

Editor: The Dean of the Faculty of Science and Technology

A doctoral dissertation from the Faculty of Science and Technology, Uppsala University, is usually a summary of a number of papers. A few copies of the complete dissertation are kept at major Swedish research libraries, while the summary alone is distributed internationally through the series Digital Comprehensive Summaries of Uppsala Dissertations from the Faculty of Science and Technology. (Prior to January, 2005, the series was published under the title "Comprehensive Summaries of Uppsala Dissertations from the Faculty of Science and Technology".) 